\title{
Vitoria-Gasteiz: la transformación de una capital autonómica (1980-2010)*
}

\section{Vitoria-Gasteiz: the transformation of a regional capital (1980-2010)}

\author{
Joseba Juaristi Linacero $^{1}$
}

\section{INTRODUCCIÓN}

En este artículo pretendemos llevar a cabo un análisis del crecimiento de la ciudad de Vitoria-Gasteiz en los treinta primeros años del período que se abre con la transición democrática en España y que se inicia en la Comunidad Autónoma del País Vasco (CAPV) con la aprobación del Estatuto de Autonomía del año 1979. A lo largo de esta etapa la ciudad de Vitoria-Gasteiz experimenta una serie de transformaciones, algunas de ellas ligadas a la nueva función de capital administrativa del nuevo ente autonómico, y otras muchas, debidas a factores propios de la nueva situación autonómica, tales como política industrial, decisiones de localización de centros universitarios, así como la adaptación de algunas instituciones alavesas ya existentes a la nueva situación. La consecuencia de todo ello es el surgimiento de una nueva imagen de la ciudad, ligada al crecimiento urbano de este período. La nueva denominación «Vitoria-Gasteiz», frente a la de «Vitoria» preautonómica, es la nueva marca que indica cierta ruptura con la imagen anterior de ciudad asociada a algunos clichés de urbe provinciana.

\footnotetext{
* El texto se enmarca en el proyecto de investigación "Las Ciudades Españolas en la etapa autonómica. Dinámicas, procesos y políticas" CSO 2009-11261, dirigido por Manuel Valenzuela Rubio.

1 Departamento de Geografía, Prehistoria y Arqueología. Universidad del País Vasco. joseba.juaristi@ehu.es.
} 
Nuestra hipótesis no consiste en «medir» el efecto capitalidad como algo separado de otros factores, sino más bien como un efecto dinamizador que impulsa y complementa ciertos efectos, no sólo económicos o de empleo, sino también iniciativas de política autonómica y local, a veces en competencia con las otras dos capitales provinciales (Bilbao y Donostia-San Sebastián), o a veces desarrollando funciones comunes e iniciativas locales propias, dando lugar a una imagen distintiva, y que se va a reflejar tanto en la estructura económica del empleo, en la estructura social o en la misma cultura urbana. De ahí que en este artículo el énfasis se ponga no solo en la función de capitalidad, sino en la política autonómica como un todo.

No intentamos hacer un estudio comparativo de los efectos de la capitalidad en otras comunidades autónomas, ya que sería muy prolijo entrar en las peculiaridades administrativas de cada una de ellas; además de los múltiples factores locales de crecimiento de las ciudades, aunque sí nos referiremos a otros ejemplos con ciertas similitudes desde algún punto de vista. Es el caso de la dinámica del crecimiento demográfico de Oviedo, la capital histórica astur, muy parecida a la de Vitoria-Gasteiz, en el contexto de comunidades autónomas que experimentan drásticamente la crisis industrial a comienzos de los años 1980. En el aspecto de la movilidad diaria residencia-trabajo, creemos que el caso de Vitoria debería compararse a otras nuevas capitales autonómicas como Mérida o Santiago de Compostela, movilidad que altera en alguna medida la organización policéntrica de las redes urbanas regionales, como ya veremos en el apartado correspondiente.

Este artículo se organiza en una serie de apartados sucesivos, tratando aspectos sectoriales del cambio experimentado por la ciudad, comenzando por un primer apartado en el que exponemos el entramado político-administrativo de la CAPV y la idea de capitalidad en el contexto. En segundo lugar analizamos el crecimiento demográfico de la ciudad a lo largo del período en comparación con la dinámica demográfica de las ciudades vascas. En tercer lugar estudiamos el crecimiento urbano de la ciudad a través de algunos indicadores sobre los nuevos barrios y la morfología urbana de la ciudad. En cuarto lugar consideramos el factor de crecimiento industrial de Vitoria-Gasteiz en la medida en que ofrece algunos rasgos distintivos en el conjunto de la economía vasca. En quinto lugar hacemos algunas consideraciones sobre el empleo en el sector público como factor reforzado por la capitalidad. En el sexto apartado presentamos cómo la función de la universidad pública en la ciudad ha reforzado la centralidad y ha contribuido a la renovación urbana en un sector de la misma. A continuación dedicamos otro apartado a las consecuencias de la capitalidad sobre la movilidad interurbana. En el último apar- 
tado hacemos algunas reflexiones sobre los aspectos de la centralidad simbólica y cultural, imagen urbana y la capacidad de representación de la ciudad. Finalmente, resumimos los aspectos anteriores en unas pocas conclusiones.

\section{El ENTRAMADO INSTITUCIONAL DEL PAÍS VASCO Y LA IDEA DE CAPITALIDAD}

El situar este trabajo dentro de un proyecto de investigación sobre capitales autonómicas obliga, al que lo escribe, a la tarea de tener que explicar, para los lectores no familiarizados con el País Vasco, algunas cuestiones relevantes de las instituciones territoriales que pueden ayudar a comprender el papel de la capitalidad de las ciudades tanto a escala de los llamados «Territorios Históricos» (provincias) como a escala de la comunidad autónoma.

Una primera cuestión se refiere a la naturaleza jurídica del carácter autonómico del País Vasco ${ }^{2}$, naturaleza que descansa en los Fueros. En el conjunto del Estado, solamente el País Vasco y Navarra tienen un sistema foral. El resto de las autonomías tienen el llamado sistema común. Los Fueros son leyes privativas de cada uno de los Territorios Históricos, preexistentes a la formación del Estado español. Estos Fueros se conservan cuando cada territorio se incorpora a un ámbito superior (Álava y Vizcaya a Castilla, en distintos momentos del siglo XIV, o Guipuzcoa a Navarra en el siglo XIII) y solo se suprimen en el siglo XIX como consecuencia de los acontecimientos bélicos de las Guerras Carlistas. Tras la segunda de estas guerras, los Fueros son sustituidos por los conciertos económicos, acuerdos que se mantendrán hasta el inicio de la Dictadura franquista, cuando Franco suprime los conciertos de Vizcaya y Guipuzcoa. Con el inicio del estado de las autonomías se reinstauran los conciertos, tal como recoge el Estatuto de autonomía de $1979^{3}$.

La condición foral es un rasgo constituyente del Estado y no una anomalía dentro del mismo, tal como lo interpretan dos visiones sesgadas, según afirma Fusi (1984). Por un lado los que consideran los Fueros como un privilegio preconstitucional o predemocrático dentro de un estado unitario, y por otro lado, los que los consideran como un pacto entre Estados, de igual a igual. El primer punto de vista es defendido tanto desde perspectivas políticas de derechas que reclaman un fuerte poder central, como desde perspectivas de izquierdas compatibles con un federalismo homogenizador. El segundo punto

\footnotetext{
${ }^{2}$ Dejamos de lado las justificaciones de la autonomía basadas en la identidad vasca, ya sea sobre hechos diferenciales étnicos, lingüísticos, o de mérito histórico.

${ }^{3}$ Ley Orgánica 3/1979 de 18 de Diciembre.
} 
de vista es defendido desde posturas nacionalistas, si bien con cierta variedad de matices.

De esta primera condición se deriva el carácter no unitario de la Comunidad Autónoma del País Vasco, en la cual los Territorios Históricos tienen un peso institucional fuerte a través de las Diputaciones ${ }^{4}$, las cuales recaudan impuestos y también tienen la función de fijar nuevos impuestos. Por encima de las Diputaciones forales, el Gobierno Vasco recibe las aportaciones económicas de éstas y fija el Cupo que se ha de pagar al Estado por los gastos correspondientes. Pero el Gobierno Vasco no recauda impuestos ni tiene la capacidad de establecer nuevos impuestos. La canalización de impuestos y gastos es por tanto disimétrica, como ha mostrado Ignacio Zubiri (2003) quien señala, según datos correspondientes al año 2001, que de los cinco niveles administrativos que funcionan en el País Vasco, desde la Unión Europea hasta los ayuntamientos, casi el 50\% de los gastos realizados en la CAPV corresponden al Gobierno Central (fundamentalmente, pensiones y prestaciones de desempleo, el 26,5\% corresponde al Gobierno Vasco, el 8,3\% a la Diputaciones forales y el $15,4 \%$ a los ayuntamientos, mientras que del lado de los ingresos las diputaciones forales recaudan el 58, 6\%, el Gobierno Central el 37,9\%, y los ayuntamientos el 3,5\%. El Gobierno Vasco, como ya hemos señalado, no tiene capacidad recaudatoria.

$\mathrm{Al}$ inicio del período autonómico no existía una normativa sobre el reparto de funciones entre el Gobierno Vasco y las Diputaciones forales, y ello suscitó un debate entre dos posturas, sobre el nuevo modelo autonómico. Por un lado los que defendían una visión más unitaria de la organización político-administrativa del territorio, debilitando la organización foral a favor de un gobierno vasco fuerte y por otro lado los que apostaban por una organización más descentralizada, dando continuidad al sistema foral en las tres provincias. Este debate dio lugar a la promulgación de la Ley de Territorios Históricos ${ }^{5}$ de 1983, y provocó a corto plazo una escisión en el partido gobernante entonces, el PNV, que produjo un nuevo partido político, Eusko Alkartasuna.

El tema de la capitalidad no supuso una cuestión esencial en el Estatuto de Autonomía, en el cual, se preveía «la designación de la sede de las instituciones comunes» mediante una ley del Parlamento Vasco. Esta Ley se promulgó en 1980, como Ley de sede de las Instituciones de la Comunidad Autónoma

\footnotetext{
${ }^{4}$ La denominación oficial es Diputación Foral (Diputación Foral de Álava, Diputación Foral de Guipuzcoa, Diputación Foral de Vizcaya).

${ }^{5}$ Ley 27/1983 de 25 de Noviembre de relaciones entre las Instituciones comunes de la Comunidad Autónoma y los órganos forales de sus territorios históricos.
} 
del País Vasco ${ }^{6}$. El laconismo de este texto legal, en el cual no aparece la palabra «capital» para designar a Gasteiz-Vitoria (sic) es comprensible debido a varias circunstancias.

En primer lugar la idea de capital no ha sido relevante dentro de los territorios forales, si exceptuamos a Pamplona, dentro del antiguo Reino de Navarra. Tanto Vizcaya como Álava y Guipuzcoa celebraban desde tiempo inmemorial reuniones de sus Juntas Generales en parajes no urbanos, así, Álava celebra su «entrega voluntaria» a Castilla en la Campa de Arriaga, Vizcaya es conocida por el valor simbólico del Árbol de Gernika, y de Guipúzcoa se conocen varios lugares de reunión en entornos rurales, hasta el siglo xviII, en que hay cuatro villas como lugares de reunión. Con el tiempo las sedes de las Diputaciones van a ser las actuales capitales, pero sin designación formularia ninguna, respondiendo a motivos prácticos, ya que las ciudades más importantes solían ser el lugar de residencia de las autoridades forales y los organismos judiciales. En estos tres territorios forales existía un sistema de gobierno dual, que separaba un tipo de leyes para los asentamientos urbanos (regidos por sus Fueros privativos otorgados en las cartas de fundación) y otro tipo de leyes para los asentamientos rurales, conocidos en Álava como «Tierras Esparsas» o en Vizcaya como «Tierra Llana». Dentro de cada territorio la competencia entre los asentamientos urbanos estaba marcada por una actitud vigilante para evitar la preeminencia formal de alguno de ellos, ratificada por un título de capitalidad.

En segundo lugar, la designación de Vitoria-Gasteiz como sede de instituciones al inicio del período autonómico se consideraba, desde la perspectiva de un cierto nacionalismo milenarista, como una solución de transición hasta que Navarra decidiera la incorporación a la CAPV, momento en el cual la capitalidad recaería en la antigua capital de los vascones, Iruña (Pamplona). Desde la perspectiva de un nacionalismo más pragmático la elección de Vitoria-Gasteiz suponía asegurarse el compromiso alavés en el nuevo proyecto autonómico, debido al menor carácter vasco y euskaldun (es decir, vasco-parlante) de los alaveses, hecho éste que ha sido subrayado anteriormente por algunos autores (Arriola Aguirre, 1991). Al mismo tiempo, se rompía la posible competencia entre Bilbao y Donostia-San Sebastián.

Pero la vinculación de Álava al nuevo proyecto autonómico no ha dependido tanto de la elección de Vitoria-Gasteiz como sede de las instituciones, sino que ya venía garantizada por el Estatuto de Autonomía, que aseguraba un «peso político» de los alaveses muy superior a su peso demográfico, al especi-

\footnotetext{
${ }^{6}$ Ley $1 / 1980$ de 23 de Mayo.
} 
ficar que «el Parlamento Vasco estará integrado por un número igual de representantes de cada territorio histórico» ${ }^{7}$.

Vitoria-Gasteiz es la sede de las instituciones comunes vascas, aunque no tiene un nombramiento formal de «capital». La reclamación del «título» de capital tiene un contenido únicamente simbólico, como la han formulado los dos últimos alcaldes 8 de la ciudad, coincidiendo, aproximadamente con el 25 y 30 aniversario del nombramiento de Vitoria como sede de las instituciones. La idea de capitalidad puede ir asociada a imaginarios muy diversos, desde aquellos que esperan mucho de la ciudad capital, hasta aquellos que piensan que los centros político-administrativos no aportan nada especial a la vida urbana, y que también llevan consigo externalidades negativas.

Sea como fuere Vitoria-Gasteiz ha funcionado en esta etapa como una capital, tal como lo demuestra la dinámica del crecimiento urbano, y el arraigo de las instituciones autonómicas en la ciudad, en relación también con otros factores que examinaremos más adelante.

\section{LA DiNÁMICA DEL CRECIMIENTO DEMOGRÁFICO}

Entre el año 1981 y el año 2011 Vitoria-Gasteiz ha crecido en cincuenta mil habitantes, pasando de 189.533 a 239.562 efectivos. No se trata de un crecimiento extraordinario, si lo comparamos con las décadas de los años 1960 y 1970, pero sí ha sido un crecimiento muy positivo en el contexto del País Vasco, dentro del cual, sobre todo en las áreas de más vieja industrialización (entorno de la Ría de Bilbao, Donostialdea, Bajo Deba) la tónica ha sido de pérdidas notables de población. Si bien Vitoria tiene una estructura industrial que difiere tanto de la de Vizcaya como de la de Guipuzcoa, no se puede afirmar que la menor incidencia de la crisis de los años 1980 haya sido el principal factor de crecimiento, o la existencia o mayor pujanza de nuevas especialidades industriales o sectores innovadores en los servicios.

La tendencia de crecimiento de la capital alavesa se ha mantenido de manera positiva, si la analizamos por quinquenios, y la comparamos con las dos áreas metropolitanas de la CAPV, correspondientes con las capitales de esos territorios históricos, y con el conjunto del territorio autonómico, tal como se muestra en la tabla 1.

${ }^{7}$ LO 3/1979 de 18 de Diciembre. Artículo 26-1. Este número igual a 25 representantes por cada provincia implica que según el Censo electoral actual, el voto de un alavés equivale al voto de 2,3 guipuzcoanos y al de 3,8 vizcaínos.

${ }^{8}$ Patxi Lazcoz (PSOE), y Javier Maroto (PP), respectivamente. 
TABLA 1

SENTIDO DEL CRECIMIENTO DEMOGRÁFICO POR QUINQUENIOS EN VITORIA Y EN LAS ÁREAS METROPOLITANAS DE LA CAPV

\begin{tabular}{cccccccc}
\hline Periodo & 1981-86 & $1986-91$ & $1991-96$ & $1996-01$ & $2001-06$ & $2006-10$ & $\begin{array}{c}\text { Balance del } \\
\text { período } \\
1981-2010 \\
\text { (habitantes) }\end{array}$ \\
\hline Vitoria-Gasteiz & + & + & + & + & + & + & 47.167 \\
Bilbao Metropolitano & - & - & - & - & + & + & -45.104 \\
Donostialdea & - & - & + & - & + & + & 3.793 \\
CAPV & - & - & - & - & + & + & + \\
\hline
\end{tabular}

Fuente: INE. Elaboración propia.

Aunque, como veremos más adelante, la industria alavesa ha tenido una dinámica más positiva que en el resto de Euskadi, consideramos que las oportunidades de empleo en el sector servicios, la atracción residencial (oportunidades de acceso a la vivienda, precio de la vivienda) y quizá también, las expectativas que crea la nueva situación autonómica, han sido factores de crecimiento más importantes.

La nueva situación autonómica no sólo ha supuesto puestos de trabajo directos en el sector público (funcionarios del Gobierno Vasco), sino también oportunidades de trabajo en otros sectores como sanidad y educación, impulsados de manera directa o indirecta por las políticas autonómicas. Por ejemplo, los requisitos de la política lingüística y educativa relativos a impulsar la enseñanza del euskera han demandado profesionales provenientes de Vizcaya y Guipuzcoa. De forma similar la localización en Vitoria del Gobierno Vasco ha incidido, a medio y largo plazo, en actividades de consultoría, hostelería, informática, transportes, medios logísticos, etc. ${ }^{9}$

El efecto de atracción de Vitoria-Gasteiz sobre las provincias vecinas, especialmente las pertenecientes a la CAPV, puede seguirse analizando los movi-

${ }^{9}$ En un artículo de Pedro Arriola (Arriola Aguirre, 1991), escrito aproximadamente en el décimo aniversario de la capitalidad, este autor valoraba especialmente el sector transportes y la hostelería. En aquellos momentos, el polígono de Lakua en el que se instaló el Gobierno Vasco era casi una localización suburbana. En un plazo más largo puede verse una mayor repercusión de la capitalidad y del hecho autonómico. 
mientos migratorios desde esas provincias, y los cambios o fluctuaciones que se han producido. La industrialización alavesa se desarrolla a partir de la segunda mitad de la década de los años 1950, como consecuencia de dos impulsos complementarios. Por un lado por la difusión de industrias guipuzcoanas localizadas en las cabeceras de los valles de ese territorio que se establecen en Vitoria (efecto de desbordamiento, o spread, propio del crecimiento polarizado), y por otro, por la oferta de suelo industrial en las proximidades del casco urbano de Vitoria, a través de políticas de promoción del Ayuntamiento de Vitoria (Arriola 1991). La industria alavesa en las décadas de 1960 y 1970 atrajo mano de obra desde provincias limítrofes, pero el origen territorial de las nuevas implantaciones industriales marcaba también los flujos migratorios.

Las tendencias mostradas en la figura 1 , auque se refieren al conjunto de Álava, pueden extenderse a Vitoria-Gasteiz, ya que la capital ha concentrado a los largo del período más del $70 \%$ de la población provincial. En este gráfico se pueden ver las tendencias divergentes de Vizcaya y Guipuzcoa en la década de 1970 (predominio de inmigrantes guipuzcoanos, en relación con la atracción industrial) y en la década siguiente de 1980 (predominio de inmigrantes

FIGURA 1

SALDO DE LOS MOVIMIENTOS MIGRATORIOS ANUALES DE ÁLAVA DESDE GUIPUZCOA Y VIZCAYA (1970-2010)

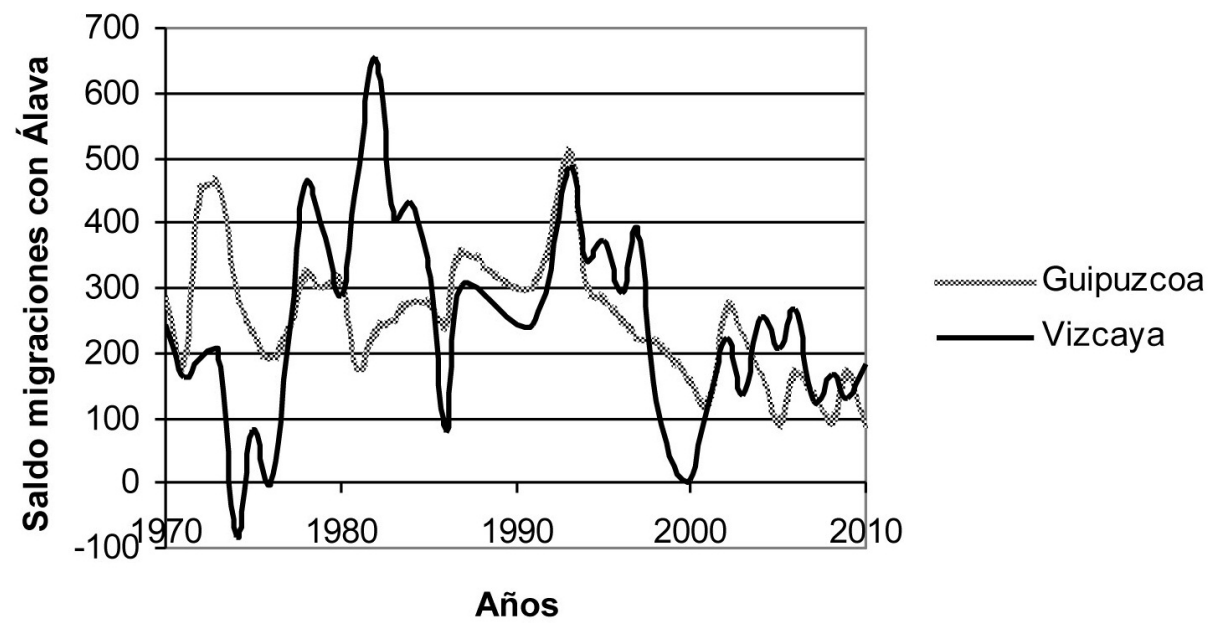

Fuente: INE. Estadística de variaciones residenciales. Elaboración propia.

Estudios Geográficos, Vol. LXXV, 276, pp. 177-218, enero-junio 2014 ISSN: 0014-1496, eISSN: 1988-8546, doi: 10.3989/estgeogr.201405 
vizcaínos, en relación con la crisis industrial en esa provincia y la atracción de empleo de Vitoria-Gasteiz). Desde mediados de los años 1980 hasta comienzos de la década de 1910 la dinámica de las dos provincias costeras es muy similar, disminuyendo en la primera década de los años 2000.

Según datos del Ayuntamiento de Vitoria-Gasteiz, en el año 2010, la composición de la población del municipio por lugar de nacimiento se repartía así: un $49 \%$ había nacido en el mismo municipio, un 26,5\% en el resto del Estado (sin la CAPV), un $11,5 \%$ en el extranjero, un $7,5 \%$ en las provincias de Vizcaya y Guipuzcoa, y un 5,5\% en el resto de Álava.

Para ver el efecto «capitalidad» sobre el crecimiento demográfico podemos comparar el incremento demográfico de Vitoria-Gasteiz, así como las pautas de crecimiento, con las de otras ciudades que alcanzan el rango de capital autonómica en este período. En los treinta años que consideramos, Vitoria incrementa su población en 50.000 habitantes, como ya hemos señalado. Logroño, capital de una autonomía uniprovincial, tiene un incremento de 41.000 habitantes, pasando de casi 111.000 habitantes a 152.000 , lo que supone un incremento proporcionado mayor que el de la capital vasca. Pamplona, igualmente capital uniprovincial, aumenta su población municipal en unos 20.000 habitantes, pero el conjunto del área metropolitana pamplonesa crece en casi 110.000 habitantes, pasando de cerca de 240.000 en el año 1981 a 349.000 en el año 2010. Otro ejemplo de considerable incremento puede ser la ciudad de Murcia que pasa de 289.000 a 442.000 habitantes. Mérida, la nueva capital extremeña aumenta unos 16.000 habitantes y el municipio de Santiago de Compostela unos 13.000 habitantes, aunque en la primera década del período autonómico, la capital gallega está experimentando un proceso de suburbanización que la convierte en una pequeña área metropolitana de cerca de 130.000 habitantes (Ferras Sexto y Lois González, 1993).

Pero quizá el ejemplo con el que la capital vasca presenta una mayor similitud es Oviedo, capital «histórica» de Asturias. Hay que tener en cuenta que en el ejemplo asturiano, el contexto económico a comienzos de la etapa autonómica es similar al vasco, de región industrial en crisis (figura 2). También habría que calibrar, en ambos casos, los fenómenos de suburbanización que se producen, quizá más patentes en Oviedo por la expansión suburbana hacia los municipios de Siero y Llanera, en el entorno más próximo de esta capital, pero también por el incremento de la movilidad en toda el área central asturiana, extendiéndose las dependencias de los lugares de residencia y trabajo a las ciudades del centro de Asturias (cuencas mineras, Gijón y Avilés). En el caso de Vitoria-Gasteiz, que cuenta con un término municipal extenso, se están produciendo algunos fenómenos de suburbanización que se extienden a otras comarcas alavesas próximas, 
como ha estudiado Galdos Urrutia (2007), pero también se ha producido un incremento de la movilidad y de dependencias residencia-trabajo que se extienden a otras ciudades y áreas metropolitanas más distantes, como veremos en el apartado sobre movilidad, lo cual puede explicar que se haya producido un aumento de la actividad económica en Vitoria-Gasteiz, sin que el incremento en términos de número de residentes en la capital haya sido proporcional.

FIGURA 2

CRECIMIENTO DEMOGRÁFICO DE VITORIA-GASTEIZ Y OVIEDO: 1980-201

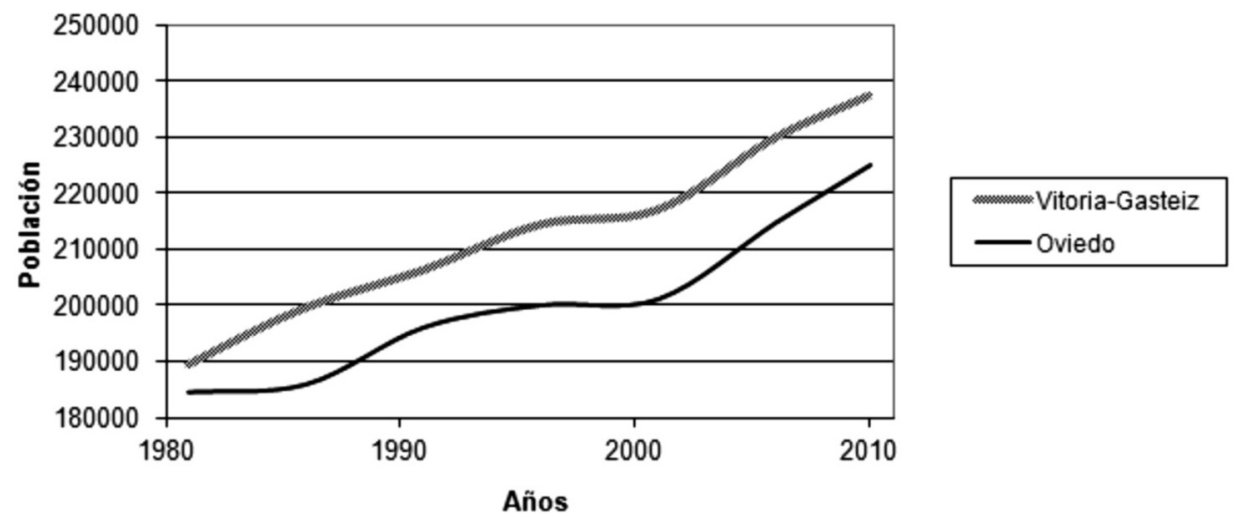

Fuente: INE. Elaboración propia.

\section{EL CRECIMIENTO URBANO Y LA NUEVA IMAGEN DE LA CIUDAD}

Si consideramos el crecimiento físico de la ciudad durante la etapa autonómica nos podremos hacer una idea de la magnitud del cambio urbano. Según el Atlas Estadístico de las Áreas urbanas Españolas (Ministerio de Vivienda, 2007), la variación del suelo artificial entre los años 1987 y 2006 estimado mediante el programa Corine Land Cover ha sido de un incremento del 51\% para Vitoria-Gasteiz, mientras que en el Bilbao Metropolitano ha supuesto un $16,5 \%$ y de un $21 \%$ en el área metropolitana de San Sebastián. La expansión del tejido urbano ha sido notoria a lo largo de todo el período y en todas las direcciones cardinales del plano urbano. En Vitoria Gasteiz el suelo artificial pasa de 2.448 hectáreas en 1987 a 3.698 en el año 2006. 
En las tres últimas décadas se han construido 47.647 nuevas viviendas lo que supone que del stock actual, el $44,5 \%$ de la vivienda vitoriana se ha producido en el periodo autonómico.

El plano de Vitoria-Gasteiz se configura como un mosaico de diferentes barrios cuya identidad todavía está marcada en buena medida por las «añadas»o épocas de crecimiento, a raíz de los diferentes impulsos económicos: los impulsos industriales de las décadas de los años 1950 a 1980, o los correspondientes a la época autonómica, desde 1980 hasta la actualidad. Todos ellos surgidos expandiendo la ciudad como «capas de cebolla» alrededor del centro histórico (Casco Antiguo y Ensanche) hacia la periferia de la ciudad, en la cual funcionan como espacios de contención los polígonos industriales creados desde la segunda mitad de los años 1950, y que se encuentran ya en contigüidad con el tejido urbano residencial. La figura 3 sintetiza esta forma de

\section{FIGURA 3}

\section{BARRIOS DE VITORIA-GASTEIZ: ETAPA A LA QUE CORRESPONDE UN MAYOR NÚMERO DE VIVIENDAS POR BARRIO}

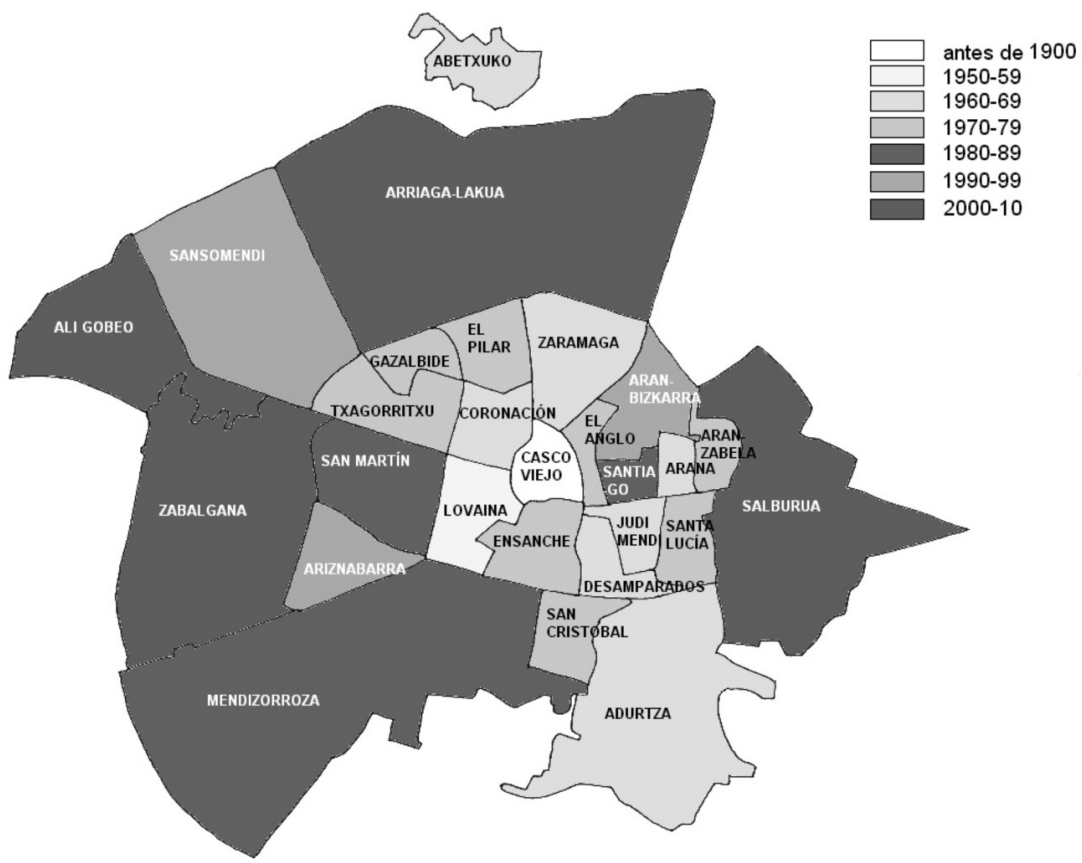

Fuente: Ayuntamiento de Vitoria-Gasteiz, 2012. Elaboración propia. 
crecimiento, reflejando la década o período correspondiente a la mayor parte de las viviendas de cada barrio.

Si bien este mapa no recoge la intensidad del fenómeno, es decir, el porcentaje del stock de viviendas que corresponde a la etapa representada, se puede comprender que conforme un barrio es más antiguo y más extenso contiene una mayor mezcla morfológica de edificios y viviendas de todas las edades, y mientras que es más reciente y de menor extensión el porcentaje es mayor ${ }^{10}$.

La mayor intensidad en la construcción de viviendas ha correspondido a la primera década del siglo XxI, y ha estado concentrada en tres barrios: Salburua, Zabalgana y Arriaga-Lakua, que contienen el $82 \%$ de las viviendas construidas en la ciudad en esa década (17.015 de un total de 20.829). Estos barrios, junto con Sansomendi, al Norte de la ciudad reúnen el 29\% de la vivienda de la ciudad.

Las nuevas zonas residenciales de la etapa autonómica, en especial las de la última década, han estado caracterizadas por ocupar zonas periféricas del casco urbano no contiguas a polígonos industriales, o bien, separadas de los mismos por parques urbanos extensivos (caso de Zabalgana y Salburua), o por situarse entre zonas residenciales que sí son contiguas a polígonos industriales (caso de Lakua, contiguo a Sansomendi y al barrio de Arriaga ${ }^{11}$ ).

Además del crecimiento residencial, la nueva imagen de la ciudad ha estado relacionada con un cambio cualitativo dirigido por políticas ambientales y sociales, lideradas en las dos primeras décadas de la etapa democrática por el alcalde José Ángel Cuerda, y que a largo plazo han dado sus frutos con la denominación de la ciudad como Capital Verde Europea en el año 2012. En el

${ }^{10}$ El crecimiento de la ciudad y la morfología urbana de Vitoria durante la etapa industrial y hasta el comienzo de la época autonómica fue estudiado con detalle por Pedro Arriola quien analizó las circunstancias económico-políticas del momento y la planificación urbana de cada barrio. Cfr.: Arriola, P. M. ${ }^{a}$ (1991). Como estudio de geografía urbana integral sobre la ciudad, cabe considerar como precedente importante el trabajo de Zárate Martín (1981). El mismo autor realizó posteriormente un artículo sobre la diferenciación social del espacio urbano en Vitoria-Gasteiz (Zárate Martín, 1988).

${ }^{11}$ El barrio de Arriaga-Lakua agrupa, de hecho, dos barrios de características diferentes, y claramente distinguibles por estar separados por el vial de Portal de Foronda, de salida de la ciudad hacia el Norte. Por un lado, el barrio de Arriaga, que crece en contacto con el polígono industrial de ese nombre, y por otro el barrio de Lakua, un sector longitudinal de manzanas extendido entre el Portal de Arriaga y la calle Duque de Wellington. Este último vial separa Lakua del barrio de Sansomendi crecido en contacto con el polígono industrial de Ali-Gobeo. El origen urbanístico de Lakua está en el plan ACTUR de 1972, que comprendía la zona entre los dos polígonos industriales del $\mathrm{N}$ de la ciudad (Arriaga y Ali-Gobeo), incluyendo los tres barrios ahora citados, de O a E, Sansomendi, Lakua y Arriaga. Cfr.: Arriola, 1991, p. 434. 
aspecto ambiental, el impulso ha venido dado por la creación a finales de los años ochenta de un Centro de Estudios Ambientales como elemento dinamizador de esas políticas, y la plasmación de un proyecto de Anillo Verde que enlaza cinco parques o áreas de interés paisajístico y natural que rodean la ciudad, así como a mejoras en las zonas verdes internas y la promoción de la educación ambiental. En lo social el Ayuntamiento de Vitoria fue pionero en cuanto al desarrollo de políticas de empleo y formación, políticas de participación ciudadana que hoy se concretan en la existencia de siete concejos territoriales dentro de la ciudad, fomento del asociacionismo (asociaciones de vecinos, de jubilados, deportivas, etc.), así como del reparto espacial de infraestructuras (centros cívicos e instalaciones deportivas de barrio), que contribuyen a la intensificación de relaciones de proximidad.

De forma similar la cooperación con países menos desarrollados o con problemas específicos ha hecho que Vitoria-Gasteiz cuente con una tasa de inmigrantes algo superior a la de los municipios de Bilbao y San Sebastián ${ }^{12}$, o que exista en la ciudad la sede de una asociación de cooperación con el pueblo saharaui amparada por el Ayuntamiento y la Diputación Foral.

Hay que resaltar que las grandes líneas de estas políticas son aceptadas, con ciertos matices, por los sucesivos equipos de gobierno, pertenecientes a distintos partidos que han estado al frente del Ayuntamiento, ya que marcan la identidad cultural de la ciudad ${ }^{13}$.

En el aspecto urbanístico, sin embargo, Vitoria-Gasteiz ha carecido de grandes proyectos, o si se quiere de «proyectos-estrella», sin que hayan tenido operaciones urbanísticas de cierta escala: la introducción de una arquitectura de impacto en los edificios públicos, la creación de grandes infraestructuras culturales, o el desarrollo de grandes proyectos asociados a la capitalidad.

En las actuaciones urbanas destacó, a comienzos de los años 1980 la regeneración del Casco Viejo, que se presentó entonces como un modelo de recuperación urbanística, a favor de la cual jugaban algunas circunstancias particulares, como el carácter original del plano urbano y el emplazamiento de la ciudad medieval, el tamaño superficial de esta zona, y el gran valor patrimonial de muchos edificios allí localizados. A treinta años de distancia puede afirmarse que se han alcanzado algunos objetivos, marcados por la presencia de infraestructuras culturales en dicho Casco, como museos, centros de con-

12 El número de inmigrantes respecto a la población total es del 9,9\% para Vitoria-Gasteiz, 8,2\% para Bilbao, y 6,6\% para San Sebastián, según datos del año 2010 (Eustat).

13 Sucesivamente PNV, EA, PNV, PSOE y PP. Los tres primeros bajo la presidencia del ya mencionado José Ángel Cuerda. 
gresos, centros cívicos y centros culturales, y en especial con la explotación como industria cultural de la Catedral de Santa María, atracción turística de la ciudad. También han sido acertados los aspectos de conservación física del Casco Medieval. No obstante, y como ha ocurrido en otros centros históricos de ciudades españolas, no se han alcanzado los objetivos de renovación comercial, teniendo aquí la función comercial un carácter más apagado que en Bilbao o San Sebastián dónde es mucho más vivo, a pesar de destacar cada vez más la hostelería. Pero tampoco se ha conseguido la revitalización residencial a través de la rehabilitación de viviendas y la atracción de nuevas clases urbanas hacia esta localización central (gentrificación), atrayendo sin embargo a poblaciones con bajos niveles de ingresos, en especial población inmigrante extranjera, que suponen aquí una tasa del $21,7 \%$, algo más del doble de la tasa de extranjería del conjunto de la ciudad.

El modelo de crecimiento urbano de Vitoria-Gasteiz ha estado marcado por la abundante disponibilidad de suelo y la facilidad del control público del crecimiento que se ha traducido en una gran expansión del suelo residencial, de acuerdo con el modelo que señaló Arriola (1991) de instituciones públicas (Ayuntamiento y Diputación) actuando en conjunción con las instituciones financieras locales y la iniciativa privada. Pero puede decirse que ha sido una expansión conservadora, pues no se han realizado iniciativas urbanísticas de riesgo, ni apuestas por infraestructuras novedosas que pudieran incidir en la base económica de la ciudad.

Si comparamos a Vitoria Gasteiz con otras ciudades medias españolas, tampoco se han dado aquí acciones de regeneración urbana destacables, como consecuencia de la recuperación de espacios obsoletos, como espacios ferroviarios, áreas industriales en declive, o el traslado fuera de la ciudad de instalaciones de cierta envergadura. La reforma ferroviaria de Vitoria-Gasteiz está aún pendiente de la construcción del nuevo trazado del Tren de Alta Velocidad, cuya estación se espera construir al Norte de la ciudad, en Arriaga, lo que sin duda creará áreas de oportunidad y espacios de nueva centralidad. Hay que decir sobre esta inercia conservadora que han existido, desde hace más de setenta años, proyectos de soterramiento del trazado ferroviario por la ciudad, y que nunca se ha iniciado. Respecto a operaciones puntuales se ha producido la reconversión de instalaciones militares en el sur de la ciudad hacia instalaciones universitarias (campus de la Universidad del País Vasco), o la reconversión del suelo dejado vacante por la planta siderúrgica Forjas Alavesas en el centro comercial Boulevard, siguiendo la tipología de un mall urbano, situado en la confluencia del barrio de Zaramaga y el polígono industrial de Betoño. 
Es cierto que ha habido nuevas construcciones de edificios públicos, como el Palacio de Justicia, en Avenida de Gasteiz, el Palacio de Congresos Europa (actualmente en remodelación), el Museo Artium de arte moderno (en terrenos de la antigua estación de autobuses), u otras instalaciones culturales de nueva creación (centro Krea, en Betoño, actualmente paralizado como centro cultural), pero las iniciativas de mayor alcance no se han llevado a cabo, como la apuesta por un recinto ferial de alcance nacional, o un gran palacio de congresos en Lakua.

Desde el punto de vista urbanístico, la condición de capital administrativa ha añadido poco, de manera directa, a la ciudad. La sede del Gobierno Vasco ocupa una parcela de cerca de poco más de seis hectáreas en Lakua, al norte de la ciudad conteniendo dos edificios gubernamentales, uno de los cuales, la sede más antigua, fue proyectado como residencia geriátrica. El más moderno, llamado Lakua-2, con fachada a la calle Donostia-San Sebastián, fue proyectado específicamente como sede gubernamental, acogiendo las instalaciones de otras consejerías y agencias gubernamentales hasta entonces distribuidas en diferentes edificios de la ciudad. Fuera de esta sede no existen otras instalaciones u oficinas, si exceptuamos algunas pequeñas agencias.

La residencia del presidente del Gobierno Vasco o lehendakari, Ajuriaenea, es un chalet cuyo primer propietario fue un industrial de maquinaria agrícola, instalado en el Paseo de Fray Francisco, una zona residencial de comienzos del siglo xx. Asociadas a Ajuriaenea se encuentran las sedes de la Presidencia del Gobierno, y la instalación del Gobierno Central o Delegación del Gobierno en el País Vasco, en las proximidades de la misma, dentro de la zona residencial del Batán, de clases acomodadas.

Además de los edificios citados se encuentra el Parlamento Vasco, ocupando un edificio neoclásico correspondiente a un antiguo instituto de Enseñanza Media. El Parlamento ha ampliado sus oficinas en un edificio próximo rehabilitado, conectado con la sede parlamentaria mediante un túnel.

En ocasiones se suele lamentar la poca presencia de lo gubernamental en la imagen urbana de Vitoria-Gasteiz, pero con toda seguridad, hubiera ocurrido algo semejante si estas sedes se hubieran ubicado en Bilbao o en San Sebastián. Tampoco Lakua es un distrito gubernamental, tal como a veces lo entienden los foráneos, ya que ese topónimo se suele emplear como equivalente al de Gobierno Vasco. Se trata de un barrio residencial nuevo con una identidad residencial en proceso de maduración, ya que los residentes son familias jóvenes aun sin mucha interacción entre ellos. En el barrio se localizan algunas instalaciones públicas (una comisaría de la Ertzantza o policía autónoma, un centro cívico, un colegio público de enseñanza primaria y abundantes espa- 
cios verdes e instalaciones deportivas) y también un edificio dedicado a centro comercial. Tal vez inducido por la demanda generada por el Gobierno Vasco, se ha instalado en las proximidades a la sede de Lakua un hotel de cinco estrellas y cerca de 150 habitaciones, con capacidad para actividades congresuales.

La imagen de la ciudad después de 30 años de etapa autonómica es la de un urbanismo residencial de calidad, con abundantes espacios verdes, recorridos por sendas peatonales y carriles-bicicleta. Es un urbanismo sin estridencias arquitectónicas postmodernas, ni grandes operaciones de reforma, ya que la abundante disponibilidad de suelo urbano ha permitido un crecimiento planificado, aunque la ciudad ha crecido en extensión, sin que el sistema de transportes públicos o los accesos a la ciudad cambiaran de manera correlativa al crecimiento residencial. Desde el año 2008 existe un metro ligero o tranvía urbano que conecta las diferentes partes de la ciudad, todavía con un trazado Norte-Sur, en forma de tenedor, quedando los nuevos barrios (Zabalgana, Salburua) fuera del alcance del mismo.

No hay nuevos iconos urbanos, aunque se haya modernizado la arquitectura de edificios institucionales, y el skyline de la ciudad lo dibujan las torres de las iglesias del Casco Antiguo. Los nuevos iconos de la ciudad son esculturas urbanas de pequeño tamaño, emplazadas en lugares céntricos. Un modo de ver la ciudad que es un reflejo de la cultura local.

\section{LA INDUSTRIA EN LA CIUDAD}

En el comienzo del período autonómico, Vitoria-Gasteiz era ya una ciudad «integrada en el País Vasco industrial» en expresión de Arriola (1991). Esta integración se debía a un rápido proceso de establecimiento de empresas industriales provenientes de las provincias de Vizcaya y Guipuzcoa, especialmente de esta última destacan las que llegaron del valle del Deba. Entre los años 1956 y 1970 se produjo una transformación drástica del perfil económico de la ciudad, cuya industrial tradicional de carácter urbano estaba marcada por las actividades artesanales (fábricas de sillas, alimentación), además de alguna especialización muy conocida como la fabricación de naipes, además de las industrias agroalimentarias y las de maquinaria agrícola.

Este proceso de industrialización tardía fue estudiado tempranamente por Azaola (1972). Posteriormente, Arriola estudió con detalle la promoción de suelo industrial (Arriola, 1991). Su carácter «revolucionario» ha sido puesto de relieve por González de Langarica, (2007). En todo caso habría que analizar, en un contexto temporal más amplio, si esta industrialización significaba 
ya un cambio estructural de la industria del País Vasco hacia una organización fordista de la economía, debido a una mayor diversificación industrial, a un aumento de las industrias de montaje, y a los cambios en la escala de las empresas. Así, la estructura empresarial de Vitoria-Gasteiz cuenta con una mayor proporción de Pymes que en la vertiente cantábrica del País Vasco.

Lo que si es cierto es que, a grandes rasgos, las industrias vitorianas han sido mucho más resistentes a la crisis industrial de comienzos de los años 1980, y que, a pesar de las reconversiones industriales que se han producido, ha habido una «continuidad de la industria» (Galdos Urrutia y Ruiz Urrestarazu, 2002). De hecho, y aunque Vitoria-Gasteiz ha experimentado el proceso de terciarización de la economía, que se ha dado de forma universal en las economías industriales, esta ciudad ocupa el primer puesto por su población activa industrial dentro del ranking de ciudades intermedias del Estado (Torres Enjuto y Álvarez González, 2010).

Vitoria Gasteiz cuenta hoy en día con una población ocupada en la industria de cerca de treinta mil empleos, lo que supone casi el 64\% del total del empleo industrial de la provincia, y a pesar de que la crisis reciente, que se detecta en el año 2009, ha supuesto una reducción de los empleos en este sector, su dinámica es en general algo más positiva que en el conjunto de la CAPV.

La composición sectorial de la industria vitoriana, es sin duda una de las ventajas competitivas que se deriva de la relativa juventud de la industria alavesa en el contexto de la CAPV, y a su vez es consecuencia de las políticas de promoción de suelo industrial que desarrolló la Diputación alavesa y el Ayuntamiento de la ciudad en los años 1950, basadas en la autonomía de estas instituciones, ya que la provincia de Álava no perdió el concierto económico con el Estado durante el franquismo, a diferencia de lo que ocurrió con Vizcaya y Guipuzcoa.

Una de las características de Vitoria ha sido no contar con una presencia destacable de los sectores más afectados por la crisis industrial de comienzos de los años 1980, como el sector metálicas básicas, si exceptuamos la empresa siderúrgica Forjas Alavesas, creada el año 1951, y que en el año 1984 se unirá al grupo Acenor. Este sector sí estaba presente, no obstante en los municipios alaveses de Llodio y Amurrio, desde los años 1940, relacionado con la fundición y la fabricación de tubos de acero. La nueva industria vitoriana se ha asociado a algunas plantas de empresas multinacionales con un gran arraigo en la ciudad, como la factoría Michelin, y la Mercedes Benz. En la actualidad hay cuatro subsectores industriales que agrupan algo más del 70\% del empleo industrial: el sector de transformados metálicos, el de caucho y materias plásticas, los vehículos de motor y, en cuarto lugar el de maquinaria, formando clusters bien definidos e interrelacionados (Torres Enjuto y Álvarez González, 2010). 
La dinámica del empleo industrial en el País Vasco, en la segunda mitad del período autonómico aquí analizado, puede verse en las figuras 4 y 5 , que representan respectivamente, las cifras absolutas de empleo industrial, y la participación en el empleo industrial de la CAPV de cada una de las provincias. En ellos podemos apreciar cómo la evolución temporal es muy semejante en las tres provincias, reflejando coyunturas semejantes (figura 4). Sin embargo Álava tiene una dinámica más positiva, aumentando gradualmente su participación en el empleo industrial de la CAPV (figura 5), llegando al final del período a concentrar el $20 \%$ del empleo industrial del territorio autonómico, prácticamente la mitad del empleo industrial de Vizcaya.

La industria vitoriana debe sus principales características a las políticas de promoción de las instituciones alavesas, especialmente la Diputación Foral y el Ayuntamiento de la ciudad. Con el inicio del período autonómico comenzará a desempeñar un papel importante las políticas de reconversión industrial del Gobierno Vasco, que más adelante serán políticas de promoción industrial y fomento de la innovación, a través de sociedades públicas como SPRI (inicialmente, Sociedad para la Promoción y Reconversión Industrial y actualmente Sociedad para la Transformación Competitiva), que cuenta a su vez con una sociedad para la gestión del suelo industrial (SPRILUR).

FIGURA 4

EVOLUCIÓN DEL EMPLEO INDUSTRIAL EN ÁLAVA, GUIPÚZCOA Y VIZCAYA (1995-2009)

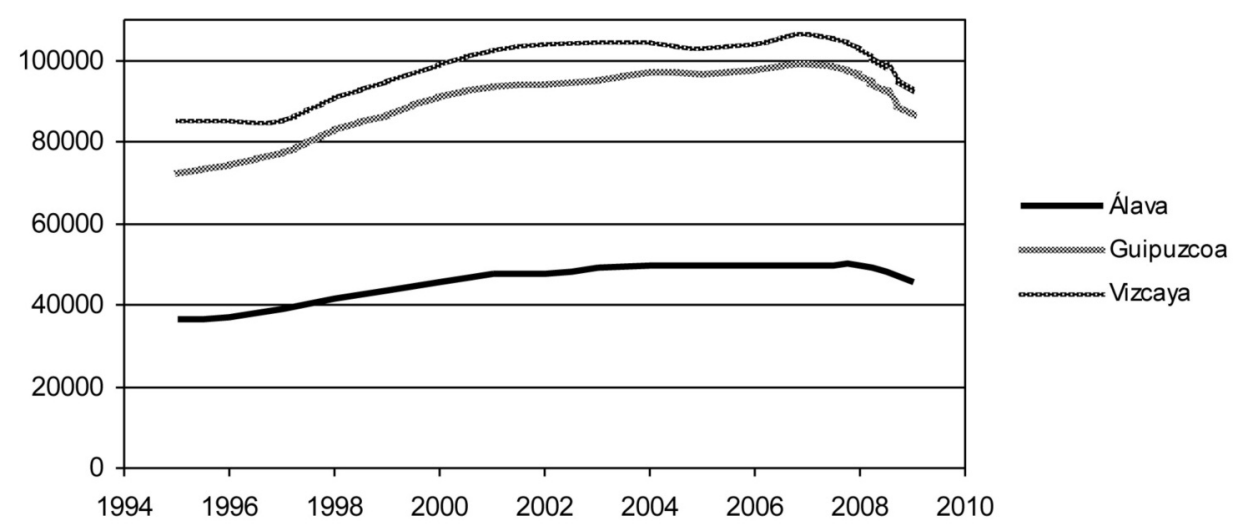

Fuente: Eustat. Elaboración propia.

Estudios Geográficos, Vol. LXXV, 276, pp. 177-218, enero-junio 2014 ISSN: 0014-1496, eISSN: 1988-8546, doi: 10.3989/estgeogr.201405 
FIGURA 5

EVOLUCIÓN DEL EMPLEO INDUSTRIAL EN ÁLAVA, GUIPÚZCOA Y VIZCAYA (1995-2009). PORCENTAJES RESPECTO AL TOTAL DE LA CAPV
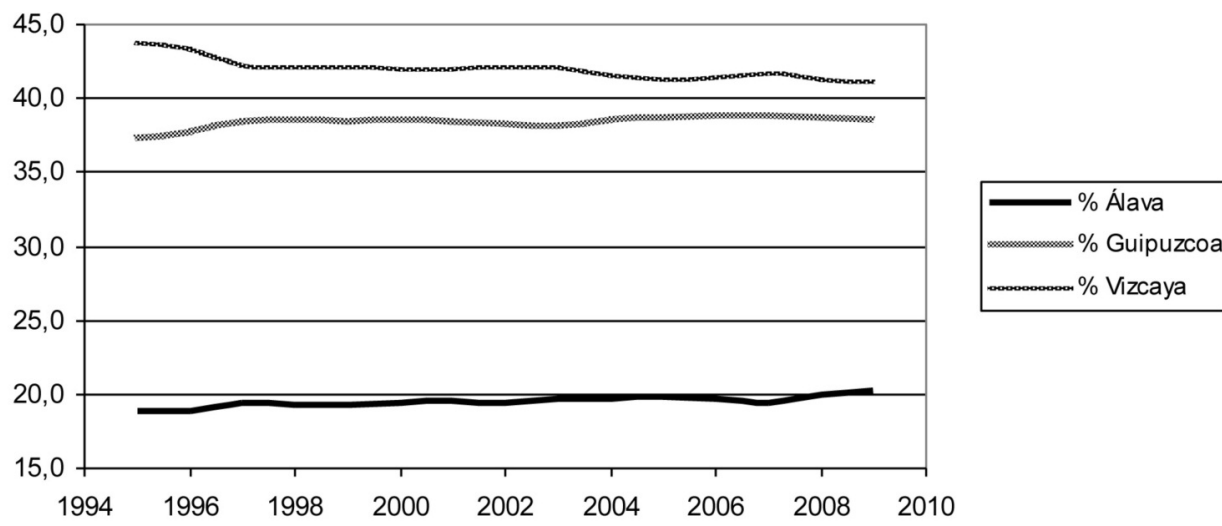

Fuente: Eustat. Elaboración propia.

El período autonómico ha supuesto la consolidación de las áreas industriales de la ciudad, y una expansión de nuevas localizaciones que se extienden a toda la provincia. Desde el punto de vista de la implantación de nuevas especializaciones industriales, Álava se ha situado al mismo nivel en los esfuerzos de innovación industrial que las provincias vascas vecinas, de mayor tradición industrial, debido a que las políticas de desarrollo industrial del Gobierno Vasco deben tratar a cada uno de los territorios históricos por igual.

La expansión del suelo industrial durante el período autonómico se ha concretado, por una parte, en la consolidación de los polígonos industriales existentes con anterioridad al mismo: Ali Gobeo, Arriaga, Gamarra y Betoño, al norte de la ciudad. (vid. figura 6), dentro de los cuales comienzan a existir instalaciones terciarias (oficinas, equipamientos municipales, etc.). A partir de 1980 se comienza a promocionar el polígono de Júndiz, en conexión con centros logísticos (Centro de Transportes de Vitoria-Gasteiz, estación de ferrocarril de mercancías), y muy próximo a Ali Gobeo, donde se localiza la factoría de Mercedes Benz.

Por otro lado, comienzan a tener importancia algunos polígonos industriales localizados ya fuera de los límites del término municipal: Gojain, en Legutiano , y Subillabide-Los Llanos, próximo a Nanclares de la Oca. Esta política descentralizadora ha sido impulsada por la Diputación Foral de Álava a través de la sociedad AAD (Álava Agencia de Desarrollo). 
Como resultado de la política de innovación industrial, se creó en 1992 el Parque Tecnológico de Alava, localizado en Miñano, dentro del término municipal de Vitoria-Gasteiz, y con fácil accesibilidad a vías de transporte y centros logísticos.

Hay que destacar, en relación con la localización industrial el papel que desempeña el aeropuerto de Vitoria-Gasteiz ${ }^{14}$, destinado a mercancías, y cuyo desarrollo puede ser un factor clave de localización de actividades empresariales.

FIGURA 6

\section{POLÍGONOS INDUSTRIALES EN VITORIA-GASTEIZ}

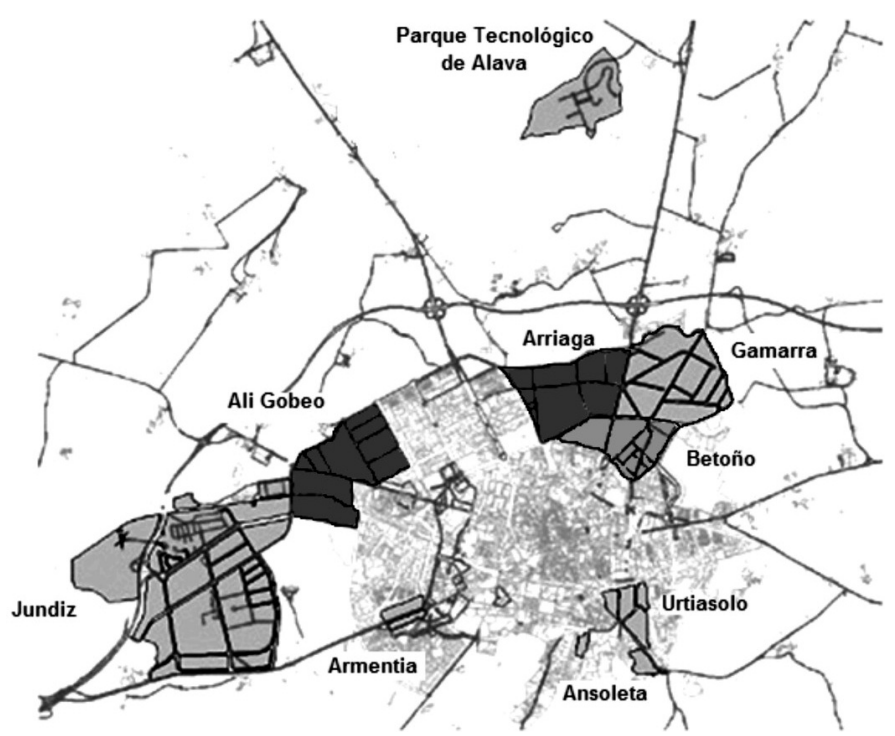

Fuente: Alavamap. http://www.alavamap.es/. Elaboración propia..

${ }^{14}$ El aeropuerto de Vitoria-Gasteiz (Aeropuerto de Foronda) fue promovido por la Diputación Foral de Álava en la etapa de la Transición Política con la idea de que fuera un aeropuerto regional, que podía llegar a ser una alternativa al aeropuerto de Bilbao (en esos años con problemas de congestión y necesidades de ampliación). El aeropuerto vitoriano se inauguró el año 1980. La escasa demanda del tráfico de pasajeros ha llevado al cese del trasporte de viajeros el año 2011, aunque con anterioridad se fue promoviendo como aeropuerto de carga, y en la actualidad ocupa el tercer puesto de los aeropuertos españoles en tráfico de mercancías. 
El Gobierno Vasco ha jugado un papel en la gestión de los nuevos espacios industriales, en colaboración con las instituciones locales y provinciales, en especial, en la creación del Parque Tecnológico de Alava y en la gestión del polígono de Júndiz, a través de la sociedad GILSA. El Parque Tecnológico de Álava está participado en un $64,07 \%$ por SPRI, un 33,61\% por la Diputación Foral de Álava y un 2,32\% por el Ayuntamiento de Vitoria-Gasteiz. En el caso del Polígono de Júndiz, la sociedad GILSA compone su capital social con la participación del 58,22\% del Ayuntamiento de Vitoria y un $41,77 \%$ de la sociedad SPRILUR (Esteban et al., 2012).

Las políticas de implantación de nuevos sectores innovadores ha tenido como consecuencia la creación de una incipiente actividad en el sector aeronáutico, en torno al grupo Gamesa, del que ha surgido la empresa Aernnova, que fabrica componentes de aeronaves. Pero, ya que la innovación implica riesgos, también ha habido otras apuestas de diversificación e internacionalización fracasadas (presencia del grupo coreano Daewoo en la industria vitoriana, que ha sido fugaz), o la misma internacionalización de industrias endógenas ha supuesto la deslocalización de puestos de trabajo en la ciudad.

\section{El EMPLEO EN EL SECTOR PÚBLICO Y LA INFLUENCIA DE LA CAPITALIDAD}

En este apartado haremos algunas consideraciones sobre el papel de la capitalidad a través del empleo público, y los efectos multiplicadores sobre otros sectores económicos de la ciudad. Aquí consideramos la influencia de la capitalidad como un efecto acumulativo que va modificando de manera paulatina las estructuras de empleo de la ciudad, pero que tiene también una influencia sobre los aspectos sociales y culturales de la ciudad, y que es difícilmente separable de otros aspectos. Este carácter estructural es un punto de vista diferente al de considerar el efecto de la capitalidad simplemente como el efecto del sector económico «Gobierno Vasco» sobre la economía de la ciudad, aunque existe un trabajo interesante al respecto (Garmendia Albarracín, 2011). Según el estudio de este autor, referido al año 2009, la capitalidad autonómica genera 4.297 puestos de trabajo (el 3,8\% del empleo de la ciudad), el impacto sobre la producción es de 378 millones de euros, y el impacto sobre la renta es de 238 millones (un 3, 4\% del PIB local). Ello supone para la Hacienda Foral alavesa una recaudación de 32 millones de euros, y cerca de 3 millones para el Ayuntamiento de Vitoria-Gasteiz.

Pero de estas variables, las que se miden monetariamente son variables de flujo, es decir, corresponden a un ejercicio anual, mientras que el empleo 
suele ser considerado una variable que se acumula, es decir un stock, y que a su vez también influye en otras variables que también se acumulan.

El mismo término «capitalidad» remite al concepto de «capital» cuya principal acepción suele ser el capital económico, aunque las extensiones metafóricas de este concepto están a la orden del día en las ciencias sociales: capital social, capital simbólico, capital humano, etc.

La capitalidad autonómica -aunque sea en nuestro caso en esta versión modesta de «sede de instituciones»- supone que hay otros elementos que acumulan, o bien más empleo, o bien mayor relevancia social, o mayor significación política que si esa función de capitalidad estuviera ausente. Por ejemplo, se supone que la Delegación del Gobierno en el País Vasco, situada en Vitoria, tiene una mayor relevancia política que las subdelegaciones situadas en Bilbao o San Sebastián, aunque su función se mantenga con un menor número de empleados.

En el caso de Vitoria, además de las instituciones ya mencionadas (Presidencia, Gobierno, Parlamento), tiene una especial importancia la Academia de la Policía Autónoma, situada en Arkaute, donde se han formado los cerca de 8.000 agentes de la Ertzaintza ${ }^{15}$ o policía autónoma vasca, y que es el lugar de celebración de muchos actos protocolarios. La decisión de localización en Vitoria de esta Academia, asocia sin duda alguna otros elementos simbólicos, por ejemplo, el uniforme rojo de la policía autónoma recuerda al único cuerpo de policía foral vasco que existió durante el franquismo: los Miñones alaveses, y la localización de la Academia recuerda la función militar de Vitoria-Gasteiz con los Centros de Instrucción de Reclutas que existieron en sus proximidades.

También existen otros factores que podríamos llamar «endógenos» alaveses que se mezclan con los relativos a la nueva condición de capitalidad, y son los referentes a la importancia y respetabilidad de las instituciones públicas locales: especialmente, la Diputación Foral y el Ayuntamiento, que en cierta manera derivan de haber conservado el Concierto Económico en la etapa anterior, lo que podríamos llamar una especie de «autonomía preautonómica». Al menos como hipótesis se puede considerar que esta autonomía preautonómica dio lugar a prácticas de gobernanza que se han traducido en la importancia relativa del sector público.

15 El Gobierno Vasco en la Segunda República funda un cuerpo de policía militar que se llamó Ertzaña, La nueva policía autonómica cuyos precedentes son las policías forales existentes en cada territorio (miñones, miqueletes), se funda en 1982 con el Gobierno de Carlos Garaikoetxea. Los primeros mandos de la Ertzaintza fueron militares de carrera. 
Un análisis del empleo en el sector público, aunque sea a escala provincial y del conjunto de la CAPV nos puede ayudar a ver esto. La tabla 2 recoge las cifras de empleo en la CAPV según varios niveles de la administración. A esta tabla hemos añadido las cifras de población total y empleo para elaborar algunos cálculos. La tabla 3 recoge las desviaciones en términos absolutos si el empleo público se reparte de forma proporcionada a la población de cada territorio $^{16}$. Con un cálculo semejante hemos elaborado la tabla 4 , que recoge las desviaciones si el empleo público se reparte de forma proporcionada al empleo total.

TABLA 2

EMPLEO EN LA ADMINISTRACIÓN PÚBLICA EN LA CAPV EN 2010

\begin{tabular}{lrrrr}
\hline & $\begin{array}{c}\text { C.A. de } \\
\text { Euskadi }\end{array}$ & Álava & Vizcaya & Guipúzcoa \\
\hline Total & 111.737 & 24.125 & 53.670 & 33.942 \\
Administración Pública Estatal & 14.602 & 2.993 & 7.063 & 4.546 \\
$\begin{array}{l}\text { Administración } \\
\text { de la Comunidad Autónoma }\end{array}$ & 64.146 & 13.336 & 31.599 & 19.211 \\
$\begin{array}{l}\text { Administración Local } \\
\text { (Ayuntamientos y Diputaciones) }\end{array}$ & 30.664 & 7.430 & 13.582 & 9.652 \\
$\begin{array}{l}\text { Universidades } \\
\text { Población Total }\end{array}$ & 2.325 & 366 & 1.426 & 533 \\
Personal ocupado 2010 & 973203 & 156075 & 498942 & 318186 \\
\hline
\end{tabular}

Fuente: Eustat.

${ }^{16}$ La fórmula empleada se deriva de los cocientes de localización de actividades y es la siguiente:

$\mathrm{W}_{\mathrm{j}}=\left[\left(\mathrm{E}_{\mathrm{ij}} / \mathrm{P}_{\mathrm{j}}\right)-\left(\mathrm{E}_{\mathrm{i}} / \mathrm{P}_{\mathrm{r}}\right)\right] \times \mathrm{P}_{\mathrm{j}}$, dónde $\mathrm{W}_{\mathrm{j}}$ es la desviación o "excedente" de empleo en la unidad espacial $\mathrm{j}$,

$E_{i j}$ es el empleo en el sector i en la unidad espacial j; $P_{j}$ es la población total existente en $j$; $E_{i}$ es el empleo total en la región en el sector i y $\mathrm{P}_{\mathrm{r}}$ es la población total de la región (la suma de todas las unidades espaciales $\mathrm{j}$ ). Para calcular las desviaciones sobre el empleo total empleamos la fórmula similar

$S_{j}=\left[\left(E_{i j} / E_{j}\right)-\left(E_{i} / E_{r}\right)\right] \times E_{j,}$, siendo $S_{j}$ las desviaciones sobre el empleo en $\mathrm{j}$ y $E_{j}$ el empleo total en $\mathrm{j}$ y $\mathrm{E}_{\mathrm{r}}$ el empleo total en la región. 
TABLA 3

DESVIACIONES EN EL EMPLEO EN LA ADMINISTRACIÓN PÚBLICA EN PROPORCIÓN A LA POBLACIÓN EN 2010

\begin{tabular}{lcrrr}
\hline & $\begin{array}{c}\text { C.A. de } \\
\text { Euskadi }\end{array}$ & Álava & Vizcaya & Guipúzcoa \\
\hline Total & 0 & 7.794 & -5.660 & -2.134 \\
$\begin{array}{l}\text { Administración Pública Estatal } \\
\text { Administración }\end{array}$ & 0 & 859 & -690 & -169 \\
$\begin{array}{l}\text { de la Comunidad Autónoma } \\
\text { Administración Local }\end{array}$ & 0 & 3.961 & -2.461 & -1.500 \\
$\begin{array}{l}\text { (Ayuntamientos y Diputaciones) } \\
\text { Universidades }\end{array}$ & 0 & 2.948 & -2.700 & -248 \\
\hline
\end{tabular}

Fuente: Eustat. Elaboración propia

TABLA 4

DESVIACIONES EN EL EMPLEO EN LA ADMINISTRACIÓN PÚBLICA EN PROPORCIÓN AL EMPLEO

\begin{tabular}{lcrrr}
\hline & $\begin{array}{c}\text { C.A. de } \\
\text { Euskadi }\end{array}$ & Álava & Vizcaya & Guipúzcoa \\
\hline Total & 0 & 6.205 & -3.615 & -2.590 \\
$\begin{array}{l}\text { Administración Pública Estatal } \\
\text { Administración }\end{array}$ & 0 & 651 & -423 & -228 \\
$\begin{array}{l}\text { de la Comunidad Autónoma } \\
\text { Administración Local }\end{array}$ & 0 & 3.049 & -1.287 & -1.761 \\
$\begin{array}{l}\text { (Ayuntamientos y Diputaciones) } \\
\text { Universidades }\end{array}$ & 0 & 2.512 & -2.139 & -373 \\
\hline
\end{tabular}

Fuente: Eustat. Elaboración propia

Según los cálculos expuestos en estas tablas puede observarse que Álava en conjunto tiene un «excedente» de empleo en el sector público respecto a la población de cerca de 8.000 empleos, de los cuales la mitad corresponden a la Administración de la Comunidad Autónoma, pero también es excedentaria en el empleo en la Administración Pública Estatal (859 empleos) y en Admi- 
nistración Local (cerca de 3000 empleos), que se justificaría fundamentalmente por los empleos de la Diputación Foral y el Ayuntamiento de VitoriaGasteiz, ya que Álava no sólo cuenta con un número de municipios muy inferior a Guipúzcoa y Vizcaya ${ }^{17}$, sino que además esos municipios son de unos tamaños demográficos muy inferiores a los de las provincias vascas vecinas. Puede comprobarse, visitando las páginas web de los ayuntamientos de las capitales provinciales vascas que el Ayuntamiento de Vitoria-Gasteiz tiene una división departamental y un organigrama tan complejos o más que los de Bilbao o San Sebastián, y quizás ello se refleje en que Vitoria-Gasteiz sea una ciudad en la cual el «municipalismo» como preocupación de los ciudadanos esté más presente. Las cifras de los excedentes, calculadas sobre el empleo total son sensiblemente inferiores, ya que Álava tiene una tasa de actividad más alta, debido a la mayor juventud de la población alavesa.

Álava, sin embargo, se aproxima al déficit en el empleo público en el sector de la universidad, quizá debido al carácter más reciente de la universidad pública en Vitoria-Gasteiz, y porque los organismos rectores de la Universidad del País Vasco se encuentran en Bilbao.

Se suele achacar que la administración pública en la ciudad de Vitoria-Gasteiz aporta poco a la vida de la ciudad debido a que una proporción importante del personal administrativo, además de los políticos (miembros del Gobierno Vasco, parlamentarios) además del personal subalterno reside fuera de la ciudad. Según Garmendia Albarracín (2011), un 45,57\% de los trabajadores de la administración tiene su residencia instalada fuera del municipio, y de ellos un 38,84\% reside fuera de la provincia. Si bien habría que matizar esas cifras atribuyendo parte de la residencia «extramunicipal» a fenómenos de residencia en localizaciones suburbanas, que se dan de manera común en muchas ciudades, y en muchas profesiones habituadas a la movilidad (empresarios, profesores, profesiones liberales, consultores, etc.). Hay que tener en cuenta que los parlamentarios electos o los cargos políticos lo suelen ser por un período de cuatro años, debiendo mantener un contacto directo con sus lugares de origen. Este fenómeno, común a la clase política en todos los territorios, hubiera sido similar si la capital hubiera estado en otras localizaciones (San Sebastián-Donostia, Bilbao, o cualquier otro emplazamiento), aunque en una ciudad de menor tamaño es un fenómeno más visible, como ya veremos en el apartado dedicado a la movilidad.

\footnotetext{
17 Álava tiene en la actualidad 51 municipios, 88 Guipúzcoa y 112 Vizcaya.
} 


\section{LA UNIVERSIDAD EN VITORIA-GASTEIZ}

La enseñanza universitaria en Vitoria-Gasteiz es principalmente un fenómeno propio del sector público, y en especial, derivado de la nueva situación autonómica. Esto no quiere decir que de no existir el nuevo estado de las autonomías Vitoria-Gasteiz carecería de universidad, sino que, probablemente, su modelo de universidad hubiera sido muy distinto al actual. Después de un período de más de treinta años Vitoria puede considerarse como una ciudad universitaria, con un campus casi consolidado, que genera una actividad y una ambiente visible en la ciudad (Araujo de la Mata et al., s/f). La Universidad ha sido también un factor de renovación urbana en un sector de la ciudad caracterizado hasta los años 1980 por la función militar. La desaparición de los Cuarteles de Flandes, al sur de la ciudad, ha permitido rehabilitar varios pabellones para acoger centros universitarios y equipamientos del campus, que también ha incorporado el antiguo hospital Psiquiátrico de Nuestra Señora de las Nieves como Biblioteca Central de la Universidad, así como su parque para uso público, dentro de la estructura de un campus fundido con el tejido urbano de la ciudad, salvo por el obstáculo de las vías de ferrocarril de Renfe, de próxima desaparición.

Los antecedentes de la Universidad en Vitoria-Gasteiz podrían haber apuntado en una dirección distinta de la que ha dado lugar a la situación actual si, por ejemplo, el modelo de universidad pública se hubiera basado en universidades provinciales, como ha ocurrido en Andalucía, Cataluña, Galicia o Castilla-León. Según ese modelo, que tiene como ventaja la proximidad de los centros de gestión y decisión y una gran autonomía, la opción suele ser el apostar por cubrir la demanda local de estudios universitarios en titulaciones muy solicitadas que tengan relación con la base económica local. Esto es también compatible con establecer algunas titulaciones muy especializadas de demanda muy dispersa que atraigan estudiantes a escala del Estado, debido a la escasez en la oferta de dichos títulos tal como ha ocurrido tradicionalmente con algunas titulaciones como ingeniería agrícola, veterinaria, y que no precisan de grandes economías de urbanización o aglomeración.

El modelo de Universidad Pública en el País Vasco, de organización unitaria con centros dispersos que se asemejan a universidades provinciales, se basa en la concentración de la demanda, lo cual permite una oferta de títulos casi enciclopédica, pero sometido a principios de administrar la escasez: no ofertar titulaciones más que en un campus, no ofertar titulaciones que ya existen en las universidades privadas existentes en el territorio. Este modelo de concentración ha dado lugar a ajustar los centros y las titulaciones a lo preexistente, pero 
también ha disparado la competencia entre las instituciones públicas (sobre todo diputaciones) en lo referente a la creación de nuevos centros y titulaciones, e igualmente la competencia entre el sector público y el privado ${ }^{18}$.

Antes del año 1980, en que se crea la Universidad del País Vasco, la enseñanza en Vitoria Gasteiz estaba muy marcada por la presencia de instituciones religiosas y eclesiásticas. La ciudad de Vitoria era conocida por la presencia de algunos colegios religiosos de prestigio, que atraían a estudiantes en régimen de internado provenientes de las élites de todo el país. La preeminencia de Vitoria en lo eclesiástico, ya que fue obispado desde el año 1861, del que se separaron las diócesis de Bilbao y San Sebastián en 1950, se tradujo en una presencia importante en el sector educativo. En la actualidad hay cuatro centros diocesanos orientados a la enseñanza secundaria y la formación profesional, además de dieciséis colegios religiosos. De hecho, la Facultad de Teología del Norte de España, situada en Vitoria es uno de los centros universitarios más antiguos de la ciudad. De origen diocesano también son los estudios de Trabajo Social, hoy en día incorporados a la Universidad del País Vasco.

De mayor tradición es la Escuela de Artes y Oficios, fundada por la Real Sociedad Bascongada de Amigos del País en 1774, que tuvo inicialmente una orientación profesional y pasó por etapas de aplicación industrial y comercial, si bien en la actualidad se dedica a enseñanzas no regladas.

En relación con la base económica industrial se creó en los años 1950 una Escuela de Peritos que ha tenido su continuidad dentro de la estructura de la Universidad del País Vasco. Finalmente, y en relación con la base económica agraria existió una institución dedicada a los estudios agronómicos: la Granja Modelo de Arkaute, creada como Estación dedicada al cultivo de la patata en 1933, que dependió del Instituto Nacional de Investigaciones Agrarias durante el franquismo, pasando en 1981 al Gobierno Vasco, y que en la actualidad está integrada en un Campus Agroalimentario asociado al Parque Tecnológico de Álava, aunque no ha dado lugar a ninguna institución universitaria.

La creación en 1977 del Distrito Universitario Vasco supuso absorber los centros universitarios existentes adscribiéndolos a la Universidad de Bilbao, incluyendo el Colegio Universitario de Álava, un embrión de universidad pública financiado por la Diputación Foral de la provincia, dependiente inicial-

18 El sector privado universitario lo constituyen fundamentalmente la Universidad de Deusto, creada por la Compañía de Jesús en el año 1886, y que cuenta con campus en Bilbao y Donostia-San Sebastián. La Universidad de Navarra tiene también algún centro en la ciudad donostiarra. En el año 1997 se crea la Universidad de Mondragón por parte de algunas empresas del grupo cooperativo de ese nombre, con centros universitarios en el Alto Deba y en San Sebastián. 
mente de la Universidad de Valladolid. En el año 1980 la Universidad de Bilbao se convierte en Universidad del País Vasco / Euskal Herriko Unibertsitatea (UPV/EHU). En la actualidad es la quinta universidad del Estado en número de alumnos.

Además de la UPV/EHU existen en la ciudad un centro asociado de la UNED, y la Facultad de Teología que hemos mencionado con un número muy reducido de alumnos, por lo que el carácter público de la enseñanza universitaria en Vitoria-Gasteiz es muy patente.

El Campus de Álava de la UPV/EHU, conocido simplemente como «Universidad» en Vitoria-Gasteiz, está formado por tres facultades universitarias (Letras, Farmacia y Ciencias de la Actividad Física y el Deporte), cuatro Escuelas Universitarias (Magisterio, Ingeniería, Trabajo Social y Estudios Empresariales), además de una Sección de la Facultad de Medicina y Odontología (que radica en Vizcaya). Se adscribe también a la UPV/EHU una Escuela de Enfermería, sin una vinculación completa. Todos los centros radican en el Campus situado al sur de la ciudad, excepto la Sección de Medicina y Odontología, próxima a la zona hospitalaria de la ciudad.

El modelo de universidad territorial que concentra la demanda hace que una gran parte del alumnado del campus de Álava provenga de las provincias vecinas, especialmente de Vizcaya y Guipúzcoa, ya que apenas existen duplicaciones en los estudios, si bien casi todas las Escuelas Universitarias tienen su origen en la demanda local de la provincia, aunque se van diversificando sus titulaciones. Así la Facultad de Letras concentra los estudios de Filología, Geografía e Historia de todo el País Vasco. La Facultad de Farmacia concentra además de esa titulación, la de ciencias ambientales y otros estudios relacionados con la alimentación. El Campus ha comenzado a desarrollar institutos universitarios de investigación en diferentes campos de ciencias y humanidades, además de equipamientos comunes.

El número de estudiantes de la UPV/EHU en el Campus de Álava ha ido creciendo en términos absolutos y relativos, llegando a cifras entre los 8.000 y los 9.000 alumnos en estudios de primer y segundo ciclo, pero también ha crecido en términos relativos, debido en parte a la diversificación de la oferta universitaria en el País Vasco, que ha afectado más a Vizcaya y Guipúzcoa. Así Vitoria ha pasado de concentrar el $11,8 \%$ de los estudiantes de la enseñanza pública vasca en el curso 1995/96 hasta el 18,0\% el curso 2009/2010.

No obstante el modelo universitario de concentración de la demanda con desconcentración de los centros en campus provinciales ha supuesto un incremento de la movilidad entre provincias de estudiantes y profesores, como veremos en el siguiente apartado. 


\section{CONSECUENCIAS DE LA SITUACiÓN AUTONÓMICA SOBRE LA MOVILIDAD DIARIA}

Como ya se ha vislumbrado en algunos apartados, la localización de la capital autonómica en un contexto de territorios forales, como es el modelo vasco, conlleva unos desequilibrios que, dentro de un territorio de pequeño tamaño, y con una localización excéntrica de las mayores ciudades ${ }^{19}$, va a generar una mayor movilidad en los desplazamientos diarios residencia-trabajo, residencia-lugar de estudios, y otros movimientos relacionados con la asistencia a servicios públicos.

Por el hecho de ser la sede de las instituciones autonómicas, en VitoriaGasteiz van a predominar los movimientos centrípetos (es decir con destinos en Vitoria-Gasteiz), desde localidades alejadas desde isócronas que se aproximan a la hora de viaje, o que incluso la superan.

Se pueden establecer diferentes áreas de alcance de estos movimientos, de acuerdo con la distancia o tiempo de viaje. Las figuras 7 y 8 recogen, respectivamente, los movimientos centrífugos (con origen en Vitoria-Gasteiz) y los movimientos centrípetos (con destino en Vitoria-Gasteiz) relativos a la relación residencia- trabajo. Los datos corresponden al censo de 2001.

Una de las principales características de la movilidad que hay que señalar es que Vitoria-Gasteiz tiene una fuerte de retención de la población residente, y por ello, en los movimientos de más de 100 personas sólo hay cuatro municipios en los cuales el número de movimientos que tienen su origen en Vitoria-Gasteiz (representados en la figura 7) es superior a los movimientos con origen en esos municipios y con destino en Vitoria-Gasteiz (representados en la figura 8). Estos municipios son Iruña de Oca (dónde se localiza un polígono industrial, además del centro penitenciario provincial), Legutiano (polígono industrial de Gojain), Salvatierra (destino de vitorianos a actividades industriales), y Mondragón, en Guipuzcoa, sede de industrias y de las oficinas del grupo cooperativo de ese nombre, a una distancia algo menor de 40 kilómetros de la capital. Para el personal técnico y directivo de las empresas de ese grupo, la capital alavesa es una opción residencial de calidad.

Respecto a los movimientos centrípetos hay que destacar varios ámbitos distintos. En primer lugar enclaves que podríamos llamar enclaves residenciales suburbanos, como Zuia, Zigoitia y Alegría-Dulantzi, donde predominan las viviendas unifamiliares de clases acomodadas y medias. En segundo lugar algunos núcleos como Miranda de Ebro, en la provincia de Burgos (centro fe-

${ }^{19}$ La CAPV tiene una superficie de 7.234 Kilómetros cuadrados. Las distancias entre capitales de provincia son de 64 kms entre Bilbao y Vitoria-Gasteiz; 98 kms entre Bilbao y DonostiaSan Sebastián, y de 103 kms entre Donostia-San Sebastián y Vitoria-Gasteiz. 
rroviario, muy vinculado funcionalmente a Vitoria-Gasteiz), o los núcleos industriales de Llodio y Amurrio (algo más vinculados a Bilbao).

Finalmente, los movimientos desde las otras capitales con destino en Vitoria muestran una gran disimetría, predominando los movimientos desde el Bilbao Metropolitano, que suman más de 3.300, mientras que los movimientos desde San Sebastián-Donostia son mucho más débiles, casi la décima parte.

La composición de estos movimientos por clases ocupacionales nos permite discernir que la capital atrae a profesionales de clases medias y acomodadas, provenientes de todo el País Vasco, pero especialmente desde Bilbao. No se trata simplemente de una mayor «suburbanización de las clases medias» como ha estudiado Susino Arbucias (2010), ya que muchos profesionales se mueven desde su residencia, en el centro de una ciudad, a su destino laboral en otra ciudad (ya sea al centro o a localizaciones suburbanas). La fricción de la distancia es decisiva en este proceso, y explica que la diferencia de distancia entre Vi-

FIGURA 7

MOVIMIENTOS RESIDENCIA-TRABAJO CON ORIGEN EN VITORIA-GASTEIZ. AÑO 2001

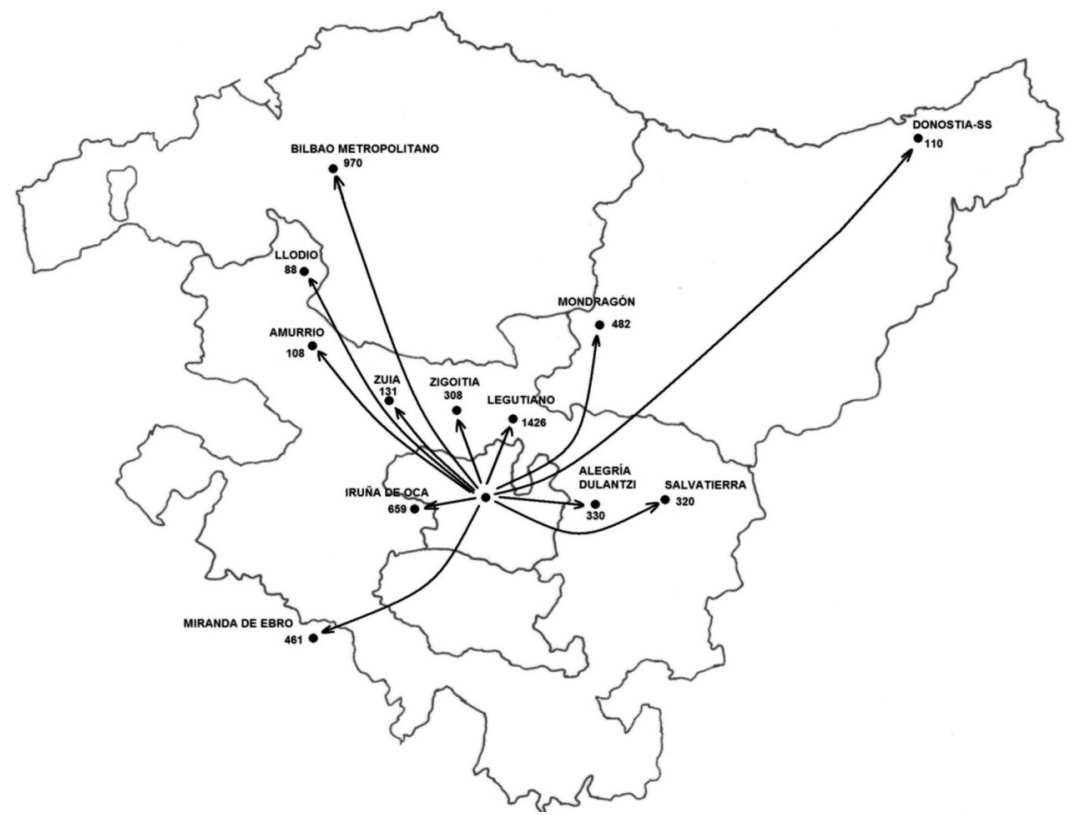

Fuente: INE, censo de 2001. Elaboración propia.

Estudios Geográficos, Vol. LXXV, 276, pp. 177-218, enero-junio 2014

ISSN: 0014-1496, eISSN: 1988-8546, doi: 10.3989/estgeogr.201405 
toria y Bilbao (cerca de $60 \mathrm{Kms}$ ), frente a la Vitoria-San Sebastián (100 Kms), sea la causa de una mayor intensidad de desplazamientos Bilbao-Vitoria.

Respecto a los movimientos residencia-trabajo agrupados por provincias hay que señalar que los movimientos con origen en Vizcaya y destino en la capital suman un total de 4.798, cifra comparable a todos los que tienen origen en Álava, exceptuando la propia capital (5.018). En comparación con estas cifras son muy menores los movimientos con origen en Guipúzcoa (1.618).

Según un estudio del Gobierno Vasco relativo al año 2007 (Gobierno Vasco, 2007), los movimientos totales con destino en Vitoria-Gasteiz serían de unas 83.000 personas diarias, de las cuales 37.000 provendrían del resto de la provincia de Álava, 19.000 de Vizcaya , 11.000 de Guipúzcoa y 15.000 de exterior de la CAPV.

En referencia a los datos sobre movimientos por motivo de estudios no existen estadísticas completas con orígenes y destinos. Según un informe de la

FIGURA 8

MOVIMIENTOS RESIDENCIA-TRABAJO CON DESTINO EN VITORIA-GASTEIZ. AÑO 2001

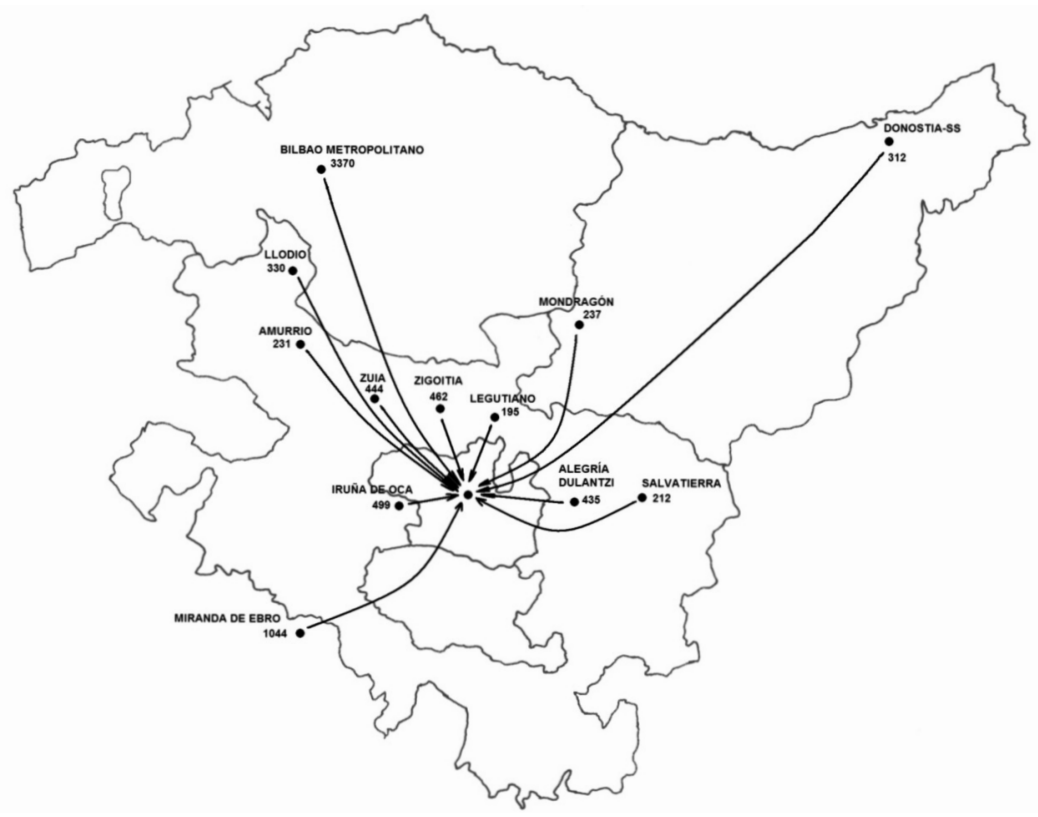

Fuente: INE, censo de 2001. Elaboración propia. 
Universidad del País Vasco (2011), correspondiente al año 2010, un 47,5\% del alumnado del Campus de Álava se desplaza al mismo desde otros municipios (3.530 personas), mientras que un 52, 5 reside en Vitoria (3.902 personas), aunque solamente el 35,5\% del alumnado está empadronado en la ciudad.

A través del Censo de 2001 podemos conocer algo del perfil ocupacional ${ }^{20}$ de las personas que se desplazan a trabajar a Vitoria-Gasteiz, comparando las cifras relativas a los residentes y los no residentes. La tabla 5 recoge estas categorías.

De acuerdo con la comparación de estas cifras mediante cocientes de localización podemos comprobar que la población que proviene de fuera del municipio destaca sobre todo en la categoría 2: de técnicos, profesionales, científicos e intelectuales, una categoría muy influida por las tareas administrativas, y asociada a la función de capitalidad. Le sigue la categoría 3 correspondiente a técnicos y profesionales de apoyo, presentando también un cociente algo superior en las categorías 1,6 y 7.

Sin duda alguna, tanto los perfiles ocupacionales de las personas que se desplazan, así como los esquemas de movilidad mostrados en las figuras 7 y 8 muestran una situación generada tanto por la localización en la ciudad de las instituciones de la CAPV, así como otras funciones que son consecuencia de la puesta en común de recursos autonómicos, especialmente, de la Universidad del País Vasco.

Estas características de movilidad son muy visibles en la ciudad, debido al gran número de autobuses interurbanos que circulan, tanto del servicio público regular como discrecionales, además de automóviles privados. La localización de la actual estación de autobuses cerca de su antiguo emplazamiento en el centro de la ciudad ${ }^{21}$ hace que tanto las salidas como las llegadas al centro de la ciudad consuman mucho tiempo, por lo que la línea concesionaria del transporte Bilbao-Vitoria realiza paradas al norte (Lakua), centro, y sur de

${ }^{20}$ Categorías ocupacionales CNO: 1) Fuerzas armadas y dirección de empresas y administraciones públicas. 2) Técnicos y profesionales, científicos e intelectuales. 3) Técnicos y profesionales de apoyo. 4) Empleados administrativos. 5) Trabajadores de la restauración, protección, vendedores. 6) Trabajadores cualificados de agricultura y pesca. 7) Artesanos y trabajadores cualificados. 8) Operarios de instalaciones y maquinaria. 9) Trabajadores no cualificados

${ }^{21}$ Anteriormente en la calle Francia, dónde ahora se encuentra el museo de arte moderno Artium. En la actualidad en las calle Los Herrán (apenas a 100 metros de distancia de la anterior). El alcalde actual (Javier Maroto, PP), tiene la intención de ubicarla al norte de la ciudad, en Lakua, en una parcela contigua a la sede del Gobierno Vasco, parcela que el alcalde anterior (Patxi Lázcoz, PSE) iba a destinar a palacio de congresos y de la música. 
TABLA 5

PERFIL OCUPACIONAL DE LAS PERSONAS QUE ACUDEN A TRABAJAR A VITORIA-GASTEIZ DESDE OTROS MUNICIPIOS

\begin{tabular}{crrrrrr}
\hline $\begin{array}{c}\text { Categorías } \\
\begin{array}{c}\text { ocupacionales } \\
\text { CNO }\end{array}\end{array}$ & $\begin{array}{c}\text { Total } \\
\text { Vitoria- } \\
\text { Gasteiz }\end{array}$ & $\begin{array}{c}\text { Residentes } \\
\text { en Vitoria }\end{array}$ & $\begin{array}{c}\text { No } \\
\text { Residentes }\end{array}$ & $\begin{array}{c}\text { (a) Residentes } \\
\text { en Vitoria }\end{array}$ & $\begin{array}{c}\text { (b) } \\
\text { \% No } \\
\text { Residentes) }\end{array}$ & Cociente b/a \\
\hline 1 & 7.713 & 6797 & 916 & 7,8 & 8,2 & 1,1 \\
2 & 14.346 & 11797 & 2549 & 13,5 & 22,8 & 1,7 \\
3 & 10.768 & 9143 & 1625 & 10,5 & 14,6 & 1,4 \\
4 & 10.069 & 9295 & 774 & 10,7 & 6,9 & 0,6 \\
5 & 13.847 & 12969 & 878 & 14,9 & 7,9 & 0,5 \\
6 & 628 & 548 & 80 & 0,6 & 0,7 & 1,1 \\
7 & 15.829 & 13849 & 1980 & 15,9 & 17,7 & 1,1 \\
8 & 16.439 & 14.726 & 1713 & 16,9 & 15,3 & 0,9 \\
9 & 8.699 & 8.046 & 653 & 9,2 & 5,8 & 0,6 \\
Total & 98.338 & 87.170 & 11168 & 100,0 & 100,0 & 1,0 \\
\hline
\end{tabular}

Fuente: INE. Censo de 2001. Elaboración propia.

la ciudad, coincidiendo con los lugares que absorben los destinos laborales de residentes fuera de la ciudad.

Parece ser que el ferrocarril de alta velocidad como alternativa, tardará algunos años más, y su estación estará situada al norte de la ciudad, muy próximo a la sede del Gobierno Vasco. Esta ubicación exigirá conexiones intermodales para poder servir a toda la ciudad.

La comparación de los movimientos con destino a Vitoria-Gasteiz con los que se producen hacia otras nuevas capitales (Santiago de Compostela y Mérida), nos confirma la importancia de la movilidad generada por el efecto «capitalidad autonómica».

Según datos del Censo de 2001, Santiago de Compostela ${ }^{22}$ recibe cerca de 25.000 trabajadores de fuera de su término municipal, aunque, como ya hemos señalado, debido a su carácter de pequeña área metropolitana, habría que

${ }^{22}$ La movilidad en Galicia ha sido estudiada de forma exhaustiva por Miguel Pazos Otón (vid. Pazos Otón, 2006). 
sustraer de esta cifra los provenientes de su área suburbana próxima (Teo, Ames, Brión, incluyendo también el municipio de A Estrada, perteneciente a la provincia de Pontevedra). Los movimientos procedentes de la provincia de A Coruña son casi 19.500, aunque desde la ciudad de A Coruña son 1.372. Los movimientos desde Vigo son mucho menores (555), o desde la ciudad de Pontevedra (305). Desde la ciudad de Ourense se dirigen 322 trabajadores, y desde Lugo, 238).

Por otro lado, Mérida recibe cerca de 6.700 trabajadores de fuera de su término municipal; de ellos, 1.102 proceden de la ciudad de Badajoz, y 528 de la ciudad de Cáceres. Pero los trabajadores provenientes de la provincia de Cáceres son sólo poco más de un 13\% del total.

Parece claro, en los tres casos expuestos aquí, que la designación de una ciudad como sede política afecta a los sistemas urbanos regionales, premiando ciertas bipolaridades urbanas entre las varias posibles (Vitoria-Bilbao, Santiago-A Coruña y Mérida-Badajoz), para los casos de Euskadi, Galicia y Extremadura, respectivamente.

\section{Centralidad Simbólica y CUltural. IMAGEN URBANA y CAPACIDAD DE REPRESENTACIÓN}

Vitoria-Gasteiz es una ciudad que representa a la pluralidad de la sociedad vasca, entendiendo esa pluralidad como una diversidad de intereses, identidades, opciones políticas y culturales, reflejando la idea, expresada por Fusi $(1984,245)$ de un territorio que contiene distintos grupos culturales y étnicos, coexistiendo pero sin fundirse en una cultura unitaria. En realidad, ese es un papel genérico de las ciudades del que ya habló Max Weber, del sinoikismo como precipitado de la ciudad.

Este carácter plural puede estar en contradicción con lo que algunos esperan de una capital política: el reflejo de una cultura unitaria como hecho distintivo, la concentración de símbolos nacionales, del poder económico, del poder militar o de la aristocracia. Otros quizá tan sólo esperen una grandeza burocrática y monumental o la concentración de un poder cultural: monumentos, museos, palacios de la música, teatros, etc.

La elección de Vitoria-Gasteiz como sede de las instituciones vascas se ha interpretado de varias maneras. Desde una perspectiva etnocentrista, que considera que las esencias vascas (raza, idioma), están mejor representadas en la vertiente cantábrica del País Vasco, o en el medio rural más que en las ciudades, la designación de Vitoria-Gasteiz parecía obedecer a establecer una «ca- 
beza de puente» (o head-link) para una especie de colonización interna (euskaldunización, difusión de la cultura vasca) de su área de influencia. Frente a esta concepción, surgió en 1989 un partido político, Unión Alavesa, que duró hasta el año 2005, y que oponía la identidad alavesa a la identidad vasca, desde una perspectiva de derechas.

Pero hay otra interpretación política, la que considera que la incorporación de Álava al proyecto autonómico vasco ha supuesto un precio muy alto (igual poder político de cada territorio en la composición del parlamento, localización de la capital en Vitoria-Gasteiz), una nueva versión de la «entrega voluntaria», pero en este caso de los territorios de Guipúzcoa y Vizcaya a Álava.

La tensión entre el Ayuntamiento y el Gobierno Vasco respecto a reivindicaciones para un mayor engrandecimiento de la ciudad muestra la retórica entre dos posturas: aquellos que consideran que Vitoria-Gasteiz debe cobrar por soportar la sede de las instituciones, y aquellos que consideran que la ciudad debe pagar por haber obtenido un beneficio. La «tercera vía» en este asunto suele ser la actitud del Gobierno Vasco (que ha actuado de manera similar bajo diferentes poderes y siglas) de dejar las cosas como están.

El hecho es que desde el año 1980 en que se designa a Gasteiz-Vitoria como sede de las instituciones, la ciudad se ha modernizado y se ha diversificado, representando el pluralismo existente en la sociedad vasca. La ciudad representa un cosmopolitismo que no es el resultado de la intensidad de relaciones comerciales con el exterior (como puede ser el caso de Bilbao), o de la proximidad a la frontera (como es el caso de San Sebastián), sino que surge de una cultura local que ve con naturalidad lo diferente y asimila fácilmente al extranjero. En este sentido podemos decir que la ciudad desarrolla un papel de representación «ecuánime» de lo que es la Comunidad Autónoma Vasca.

Una consideración que creemos importante es que, desde que se inició la etapa autonómica, las ciudades del País Vasco, y no sólo las capitales provinciales, han entrado en una suerte de «economía de red» que quizá es compleja de gestionar o controlar, pero que funciona de alguna manera, mediante mecanismos de competencia y cooperación, sujeta a reglas, convencionalismos, valores, e incluso «reglamentos» implícitos (Storper y Walker, 1989). Esta economía de red es inédita, ya que no existía en la etapa preautonómica, pero que se manifiesta en una continua vigilancia de los logros y fracasos de las ciudades vecinas, un mayor conocimiento de las élites de agentes locales y una evaluación de las acciones de la política de los vecinos (a escala local, provincial y autonómica). 
De cara al exterior (es decir, la Comunidad Europea) este tipo de sinergias se ha empaquetado bajo una etiqueta de marketing urbano llamado «Euskal Hiria» (o "ciudad vasca») ${ }^{23}$ en el que se resalta lo cooperativo, lo diverso, lo consensuado, y se ocultan las dificultades, los fracasos, las duplicidades. Aunque las ciudades son imprescindibles para la gobernanza de las regiones en general, y en el País Vasco en particular, la desaparición de las identidades urbanas subsumidas bajo una única «ciudad vasca» no parece haber convencido a cada uno de los mandatarios de las capitales vascas.

En el inicio de la etapa autonómica se presentaba la complementariedad de las funciones de las ciudades vascas señalando que Bilbao era una capital «económica», San Sebastián una capital cultural y Vitoria-Gasteiz una capital administrativa. De hecho ninguna ciudad puede considerarse a la cabeza en cada uno de de esos tres aspectos, y rivalizan en cada uno de ellos. La búsqueda de reconocimiento internacional y de nueva imagen urbana es una muestra de ello. Vitoria-Gasteiz ha logrado el nombramiento de «Capital Verde» europea para el año 2012, y Donostia-San Sebastián será capital cultural europea el año 2016. La insistencia en aspectos culturales sectoriales lleva a cierta especialización. Así en los espectáculos deportivos, la incapacidad de ser un referente destacable en fútbol para la capital alavesa ha llevado a un fuerte y rápido arraigo del deporte del baloncesto en torno al club Baskonia.

Esto mismo también ha ocurrido con la diversificación cultural en cuanto a ciertos eventos como el Festival de Jazz de Vitoria-Gasteiz, que se celebra desde 1977 todos los años en el mes de julio, y que es un referente internacional, atrayendo a más de 80.000 espectadores en el total de sus actividades. Más reciente es el festival de rock indie Azkena Rock Festival, realizándose desde hace 10 años.

Pero hay infraestructuras culturales cuyo funcionamiento y demanda dependen de factores como la masa demográfica y la accesibilidad urbana. Vitoria posee una buena oferta de museos tanto de tipo tradicional como moderno. Los «motores» de la atracción cultural de Vitoria-Gasteiz son la Fundación Catedral de Santa María, que ha promovido las visitas a ese templo como un

${ }^{23}$ Euskal Hiria ("Ciudad Vasca", fonéticamente similar a "Euskal Herria” o Pueblo Vasco, y también País Vasco) es una idea genérica de considerar los valores cívicos del País Vasco, y su carácter cosmopolita, por encima de los clichés asociados a la ruralidad y el nacionalismo radical, neologismo avalado por el escritor Bernardo Atxaga. Como idea de marketing urbano fue promovida por el Gobierno Vasco para difundir la idea de un País Vasco urbano policéntrico, y variado, un ejemplo de región urbana europea en un momento en el que la Estrategia Territorial Europea ponía en valor la idea de policentrismo. Cfr.: van Houtium y Lagenijk, 2001. 
ejemplo distintivo de arqueología de la arquitectura e intervención arqueológica, y el museo Artium de arte moderno. El número de visitas anuales a cada uno de esos museos supera las cien mil, pero quedan muy por debajo de otros centros museísticos vascos, como por ejemplo el Museo de Bellas Artes de Bilbao o el Kutxa Espacio de la Ciencia de San Sebastián, que duplican esas cifras (por no hablar del Museo Guggenheim que las multiplica por diez). Esa falta de «masa crítica», además de la falta de continuidad en algunos proyectos culturales (Centro Cultural Montehermoso, Krea), y quizá también la falta de raigambre histórica hacen que la proyección cultural de la ciudad quede muy por debajo de lo que pudiera esperarse de una capital autonómica.

Algo parecido puede decirse de las actividades congresuales y de la misma «capacidad de representación» de la ciudad para mostrase como capital. Una prueba de ello es el fracaso del proyecto de crear un gran centro internacional de congresos, exposiciones y artes escénicas, en una parcela contigua a la que ocupa la sede del Gobierno Vasco en Lakua ${ }^{24}$.

En cuanto a la capacidad de representación del País Vasco de cara al exterior, Vitoria-Gasteiz tiene algunas desventajas, como es el estar situada en el interior, carecer de una accesibilidad en cuanto a transporte internacional de pasajeros, y también, en no responder a algunas imágenes sobre Euskadi que se desean promocionar. Así, Donostia-San Sebastián y Bilbao suelen acoger muchas actividades de representación y de relaciones oficiales del Gobierno Vasco. La primera de estas ciudades suele ser elegida porque muestra un País Vasco de calidad de vida, hedonista, y vinculado a la cultura europea (San Sebastián suele presentarse como una «eurociudad» que llega hasta Bayona), imagen que debe también mucho al conocido Festival de Cine. La segunda suele ser elegida por dos tipos de razones: o bien por motivos logísticos, por la facilidad de acceso al transporte aéreo (el Gobierno Vasco posee una sede, el Palacio Artaza, para reuniones de este tipo, relativamente próximo al aeropuerto de Loiu), una mayor oferta hotelera, y también por mostrar el poder urbano y económico de Bilbao, su área metropolitana y su puerto. Bilbao además, es la sede de la radio-televisión autonómica (EITB), y la sede del Tribunal Superior de Justicia del País Vasco

${ }^{24} \mathrm{El}$ proyecto, con un coste total de 157 millones de euros preveía reunir en la parcela de la Plaza de Euskaltzaindia un gran centro internacional de Congresos, Exposiciones y Artes Escénicas, que iba a entrar en funcionamiento en el año 2014. Dicho centro incluía una gran edificio para exposiciones de 40.200 metros cuadrados, un palacio de congresos de 17.800 metros cuadrados y dos salas para música de cámara y sinfónica, respectivamente, de 3.700 y 9.300 metros cuadrados. El proyecto fue promovido por el alcalde socialista Patxi Lázcoz. Con el cambio de gobierno en el ayuntamiento parece que el solar se va a destinar a estación de autobuses. 


\section{CONCLUSIONES}

La nueva situación autonómica en su doble dimensión, por una parte, de nuevas políticas económicas sectoriales (fomento de la industria, creación de infraestructuras, políticas educativas dirigidas a la euskaldunización, a la creación de estudios universitarios, políticas sociales de ordenación de servicios sanitarios y asistenciales), y por otra de políticas territoriales de localización, ha tenido consecuencias tanto en la estructura interna de la ciudad de VitoriaGasteiz, como en la nueva situación del sistema urbano regional del País Vasco.

En el primer aspecto, desde la designación de Vitoria-Gasteiz como sede de las instituciones autonómicas de Euskadi puede observarse un crecimiento y una transformación de la ciudad muy importante. Vitoria-Gasteiz es una ciudad muy conocida por sus estándares urbanísticos, por su calidad de vida basada en el medio ambiente y en la diversidad social y cultural. Desde el punto de vista económico, la ciudad ha mostrado una mayor pujanza que las zonas de antigua industrialización del País Vasco, y qué duda cabe que la capitalidad ha contribuido a aumentar el empleo, a mejorar su calidad, y a modernizar el sistema productivo. Las políticas autonómicas han ayudado a esta modernización y cambio de imagen, tanto las políticas industriales como las políticas de distribución de establecimientos del sector público, especialmente educación universitaria.

El modelo de crecimiento urbano de estas tres décadas ha sido un modelo expansivo en el aspecto residencial, bajo unas condiciones que ya estaban establecidas con anterioridad, basadas en la disponibilidad abundante de suelo y el predominio de la gestión pública de esta expansión, lo que ha dado lugar al surgimiento de nuevos barrios de la etapa autonómica. Este modelo expansivo no se ha producido en otras ciudades vascas, sumidas en procesos de reconversión del suelo industrial y regeneración urbana. Pero Vitoria-Gasteiz tampoco ha apostado por introducir grandes innovaciones en la reforma de la ciudad, como nuevas infraestructuras de transporte, espacios de nueva centralidad o grandes proyectos culturales.

Por otra parte el mantenimiento de las sedes institucionales y de centros que sirven al conjunto de la CAPV implica unos costes de movilidad altos. Hay más de 12.000 puestos de trabajo en la ciudad que son ocupados por personas que se trasladan diariamente desde lugares lejanos, muchos de ellos desde otras provincias.

Respecto a la capacidad de representación, Vitoria-Gasteiz se sitúa en inferioridad de condiciones frente a San Sebastián o Bilbao. Esta inferioridad reside, en parte, en su condición de ciudad interior, algo alejada de las infraes- 
tructuras de transporte más importantes, pero también en el hecho de que Vitoria-Gasteiz es la capital de una comunidad autónoma no-unitaria, en el sentido político, y ésta es una diferencia fundamental del País Vasco respecto a otras comunidades autónomas, como ya hemos puesto de relieve en el apartado del entramado institucional. Vitoria puede reclamar por ley su derecho a que se localice en la ciudad las sedes comunes de Gobierno (Gobierno Vasco, Parlamento y residencia del presidente), pero es más difícil reclamar que los nuevos equipamientos o infraestructuras comunes «centrales» se localicen ahí, ya que el carácter foral de los territorios impedirá las políticas de concentración y centralización.

Desde el punto de vista de la incidencia de la nueva capital en el sistema urbano, habría que analizar con mayor profundidad cómo funcionan las «economías de red» regionales a partir del inicio de los procesos de constitución de las nuevas comunidades autónomas. El caso de Vitoria-Gasteiz sirve para ver que hay sectores, como el universitario, que funcionan de manera centralizada y unitaria, mientras que el sistema político administrativo está descentralizado.

Por otra parte, está claro que la decisión de localizar el poder político de una comunidad autónoma en una ciudad tiene sus consecuencias en el sistema urbano regional, quizá no tanto en el papel de motor del crecimiento urbano, como ha señalado Campesino Fernández (2009), sino como elemento que dinamiza y refuerza ciertas bipolaridades urbanas, que pueden ser tanto funcionales como políticas. Los políticos regionales han tendido a considerar el problema de la capitalidad como algo ajeno a la cuestión más general de la ordenación del territorio, y de hecho, las capitales se designan con anterioridad a la promulgación de la leyes de ordenación del territorio autonómicas, pero es necesario que se analicen las relaciones entre las políticas de localización y la ordenación del territorio.

Fecha de recepción: 04/06/2013.

Fecha de aceptación 20/02/2014.

\section{BILIOGRAFÍA}

Araujo de la Aata, A. et al. (s/f): Impacto económico e imagen percibida de la Universidad del País Vasco en Alava. Bilbao, Vicerrectorado del Campus de Alava, Servicio Editorial, Universidad del País Vasco.

Arriola Aguirre, P. M. (1991): "Vitoria-Gasteiz: la «discreta» capital de Euskadi". Boletín de la AGE, 13, pp. 143-163. 
Arriola, P. M. (1991): La producción de una ciudad-máquina del capital: Vitoria-Gasteiz. Bilbao, Servicio Editorial, Universidad del País Vasco.

Azaola, J. M. (1972): Vasconia y su destino. Madrid, Revista de Occidente, 551 pp.

Campesino Fernández, A. J. (2009): "La organización urbana de Extremadura", en F. Rodríguez Gutiérrez: Las áreas metropolitanas en España. La nueva forma de la ciudad. Oviedo, Universidad de Oviedo, pp. 181-204.

Esteban Galarza, M.; Álvarez González, I. y Torres Enjuto, M. C. (2012): "Políticas de suelo industrial en Álava". Boletín de la AGE, 58, pp. 133-156.

Fusi J. P. (1984): El País Vasco. Pluralismo y nacionalidad. Madrid, Alianza Editorial.

Ferras Sexto, C. y Lois Gonzälez, R. C. (1993): "Estructura urbana de las áreas Metropolitanas gallegas. La estructura urbana de Santiago. ¿Un área metropolitana en proceso de formación?" Papeles de Geografía, 19, pp. 115-124.

Galdos Urrutia, R. (2007): "Nuevas tendencias en la dinámica demográfica del territorio alavés", en Micaela Portilla. Omenaldia. Homenaje. In Memoriam. Actas de la Jornadas Congresuales. Vitoria-Gasteiz, Eusko Ikaskuntza, Diputación Foral de Álava, pp. 229-236.

Galdos Urrutia, R. y Ruiz Urrestarazu, E. (2002): "La continuidad de la industria: estructura y localización industrial en el País Vasco". Eria, 59, pp. 357-370.

Garmendia Albarracín, J. M. (2011): Estudio sobre la incidencia económica de la capitalidad autonómica en Vitoria-Gasteiz. Vitoria-Gasteiz, Universidad del País VascoEuskal Herriko Unibertsitatea, Departamento de Economía Aplicada.

Gobierno Vasco (2007): Estudio de la movilidad de la Comunidad Autónoma Vasca. Bilbao, Departamento de Transportes y Obras Públicas.

González de Langarica, A. (2007): La ciudad revolucionada. Industrialización. Inmigración, urbanización (Vitoria-1945-1965). Vitoria-Gasteiz, Ayuntamiento de VitoriaGasteiz.

Houtum, H. Van y Lagendijk, A (2001): "Contextualising regional identity and imagination in the construction of Polycentric urban regions: the cases of the Ruhr area and the Basque Country". Urban Studies, 38/4, pp. 747-767.

Pazos Otón, M. (2006): "New trends in mobility and lifestyles: implications for the urban system in Galicia", en Lois González, R. C. (ed.): Urban changes in different scales: systems and structures. Santiago, Universidade de Santiago de Compostela, pp. 205-222

Storper, M. y Walker, J. (1989): The capitalist imperative. Territory, Technology and Industrial Growth. Nueva York, Basil Blackwell, 279 pp.

Susino Arbucias, J. (2010): "La movilidad social diferencial en la reconfiguración metropolitana", en J. M. Feria Toribio y J. M. Albertos Puebla: La ciudad metropolitana en España: procesos urbanos en los inicios del siglo XXI. Cizur Menor, Civitas. Thomson Reuters, pp. 149-173.

Torres Enjuto, C. y Álvarez González, I. (2010): "Vitoria-Gasteiz", en Méndez Gutiérrez del Valle, R. (ed.): Estrategias de Innovación Industrial y Desarrollo Económico en las ciudades intermedias de España. Bilbao, Fundación BBVA, pp. 347-383. 
Universidad del País Vasco, Consejo de Gobierno (2011): Informe sobre Transporte y Movilidad sostenible en la UPV/EHU. Bilbao, Universidad del País Vasco.

Zárate Martín, M. A. (1981): Vitoria. Transformación y cambio de un espacio urbano. Vitoria-Gasteiz, Ed. Institución Sancho El Sabio/Caja de Ahorros Municipal de Vitoria, 520 pp. y apéndice documental.

Zárate Martín, M. A. (1988): "Bienestar social y diferenciación interna del espacio urbano. Vitoria-Gasteiz". Espacio, Tiempo y Forma, 31, pp. 63-178.

Zubiri Oria, I. (2003): "El sector público del País Vasco en la actualidad". Ekonomiaz, 54, pp. 68-103.

\section{RESUMEN}

Vitoria-Gasteiz ha sido la ciudad vasca que ha experimentado un mayor crecimiento urbano durante el período autonómico analizado (años 1980 a 2010). Este crecimiento no ha sido meramente un incremento cuantitativo, demográfico o físico, sino que ha conllevado una transformación de la imagen de la ciudad, de la estructura del empleo y de las funciones urbanas.

Entre los factores de esta transformación destacan la designación de la ciudad como sede de las instituciones autonómicas por parte del Parlamento Vasco, pero también ha influido de forma decisiva el papel de políticas autonómicas concretas, tanto de localización de establecimientos de instituciones comunes (Academia de la Policía Autónoma, Universidad), como políticas económicas de innovación y promoción industrial.

El resultado de ambos efectos ha sido un cambio radical respecto al modelo de ciudad anterior.

PAlabras Clave: cambio urbano; capitalidad regional; crecimiento urbano; VitoriaGasteiz; País Vasco.

\section{Abstract}

Vitoria-Gasteiz has been the Basque city that has experienced the greatest growth during the period analysed here (1980 to 2010). This growth has been not merely a quantitative increase, demographic or physical, but it implies a structural transformation of the employment, urban functions and the image of the city itself.

Factors for this transformation include the designation of the city as the seat of the autonomous institutions, but also has been decisive the role of specific policies, both the location of other regional institutions such as the Basque Police Academy, and new faculties of the public university, and also economic policies of innovation and industrial promotion.

The result of both effects has been a radical change from the previous city model.

KEY WORDS: urban change; autonomic capital; Vitoria-Gasteiz; Basque Country. 


\section{RÉSUMÉ}

Vitoria-Gasteiz a été la ville basque qui a connu la plus forte croissance urbaine au cours de la période analysée régional (années 1980-2010). Cette croissance n'a pas été simplement une augmentation quantitative, démographique ou physique, mais a conduit à une transformation de l'image de la ville, la structure de l'emploi et des fonctions urbaines.

Parmi les facteurs de cette transformation inclure la désignation de la ville comme siège des institutions autonomes par le Parlement basque, mais aussi une influence décisive sur le rôle des politiques régionales spécifiques, les deux établissements localisation des institutions communes (Académie Autonome de police, Université), l'innovation et les politiques économiques de promotion industrielle. Le résultat de ces deux effets a été un changement radical par rapport au modèle de la ville précédente.

MotS-CLÉs: capital autonome; la croissance urbaine; Vitoria-Gasteiz; Pays Basque. 